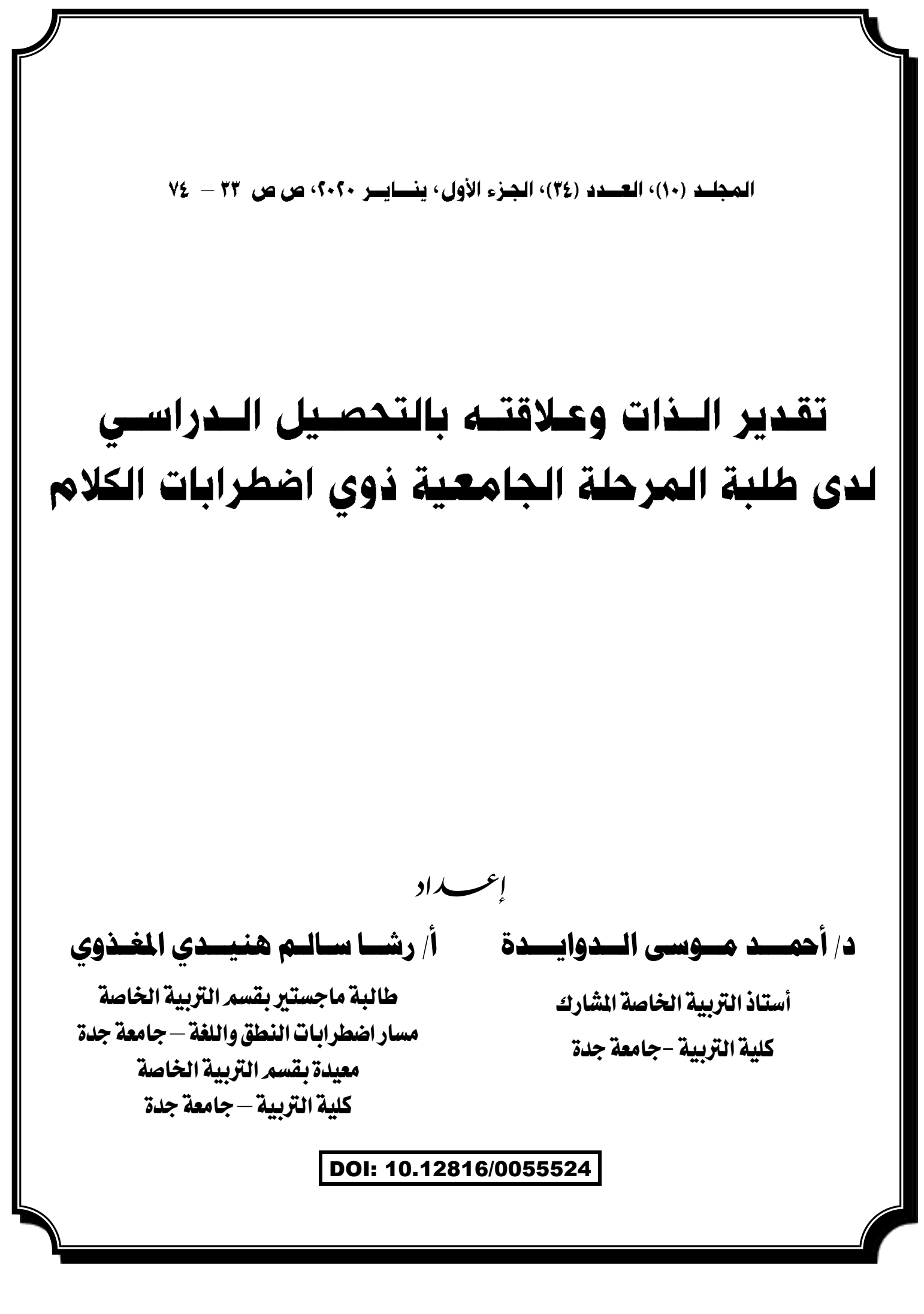




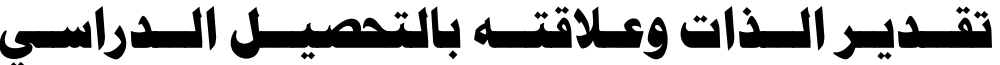

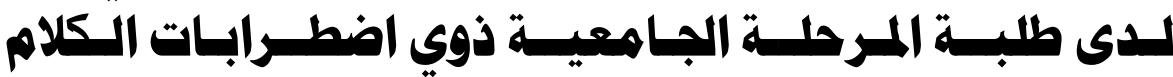 إيــــ}

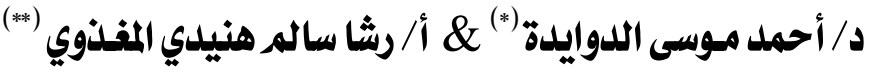

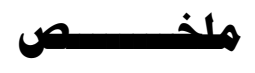

هدف البحث الحالي إلى الكثف عن علاقة تقدير الذات بالتحصيل الدراسي لاى طلبة المرحلة الجامعية ذوي اضطرابات الكلام. اتبع الباحثان المنهج الوصفي (الارتباطي)، وذلك ببناء أداة البحث المكونة من ثلاثة أقسام هي: القسم الأول: يحتوي على مقدمة تعريفية بأهداف البحث، ونوع البيانات والمعلومات التي يود الباحثان جمعها، القسم الثاني: يحتوي على البيانات الأولية الخاصة بأفراد عينة البحث، والقسم الثالث: يتكون من استبانة تقدير الذات (9 ( ) عبارة. وتكونت عينة البحث من (9ه 1) طالباً وطالبة من طلبة المرحلة الجامعية ذوي اضطرابات الكلام الملتحقين بالجامعات في المملكة العربية السعودية، خلا الفصل الدراسي الأول من العام الجامعي

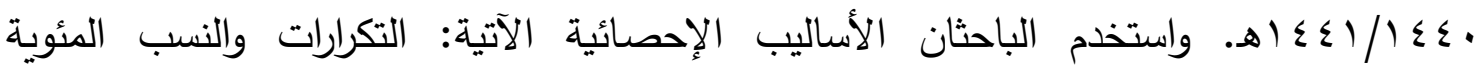
والمتوسطات والانحرافات المعيارية، معامل الارتباط لبيرسون، اختبار ت لعينة واحدة. توصلت نتائج البحث الحالي إلى مستوى متوسط من تقدير الذات بلغ (7,V9 ). كما أشارت نتائج البحث إلى وجود علاقة ارتباطية طردية دالة إحصائياً عند مستوى (1 +., ) بين تقدير الذات والتحصيل الدراسي لدى طلبة المرحلة الجامعية ذوي اضطرابات الكلام. الكلمات المفتاحية: تقدير الذات، التحصيل الدراسي، اضطرابات الكلام. 
د/أحمدالدوايـلة \& أ/رشا المفذوي تقير الذات وعلاقته بالتدصيل الدراسي لدى طلبة المرحلة الجامعية ذوي اضطرابات الكلام

Self-Esteem and its Relationship to Academic Achievement among Undergraduate Students with Speech Disorders

By

Dr. Ahmad Aldawaideh ${ }^{(*)}$ \& TA. Rasha Almughthawi ${ }^{(*)} \square$

\section{Ahstract $\square$}

The present study aimed to identify the relationship of self-esteem with academic achievement among undergraduate students with speech disorders. To achieve the study objectives, the researcher adopted the descriptive approach by developing the study tools which consisted of three sections; section I contained an introduction to the objectives of the study, and the type of data and information that the researcher would like to collect, section II contained the raw data for the members of the study sample, and section III consisted of self-esteem questionnaire (19 phrases). The study sample consisted of (156) university students with speech disorders enrolled in Saudi universities during the first semester of the academic year 1440/1441.

The researcher used the following statistical methods: frequencies, percentages, averages, standard deviations, Pearson correlation coefficient, One- Sample T-Test. The results of the present study identified the average level of self-esteem was (46.79 (among undergraduate students with speech disorders. The results also indicated a statistically significant positive correlation at the level (0.01) between self-esteem and academic achievement of undergraduate students with speech disorders

Key words: Self-Esteem, Academic Achievement, Speech Disorders.

(*) Associate Professor of Special Education - College of Education - University of Jeddah.

$(* *)$ Teaching Assistant - College of Education - University of Jeddah. 
يعدّ التعليم الجامعي أحد المراحل المهمة في دعم التنمية البشرية، كون الطالب الجامعي من أهم العناصـر التـي يعتمد عليهـا المجتمـع في تحقيق أهدافه، ومـن الضـروري تهيئـة المنـاخ الجـامعي المناسـب والتغلب على المعوقـات ومواجهـة أيّ مشكلات تعيق قدرة الطالب على التعلم؛ فالمرحلـة الجامعيّة هي مرحلة التخطيط للحياة العمليّة والمضي قدمًا في المجالات الوظيفية المختلفة. ومن جهة أخرى، يلعب التواصل دورًا مفصليًّا في عملية التعلم فدونه لا يتم التعلُّم، وهذا بدوره يقود لأهميّة التفاعل بين الأستاذ والطالب وبين الطلاب أنفسهم، حيث إنّ التّاعل الاجتماعي في بيئات التعلّم من أبرز العوامل المؤثّة في نجاح الطلبة، مما يساعد في تحقيق توافق دراسي ملائم وتحصيل دراسـي جيّد للطـلاب، وفي المقابـل يعـاني بعض الطـلاب في مختلف المجتمعات مـن اضطرابات الكلام على اختلاف أنواعها: النّطق، الصسوت، والطلاقة والتي من شأنها الإسهام في إعاقة الفرد عن أداء بعض أدواره المتعدّدة في منظومته الاجتماعية (الغامدي، 9 . . ب). ويرى عيد (10 r) أنّ الكلام هو سبيل مهم من سبل الاتصال النّقسي، وهو وسط التواصل الفـي الذي يستخدم الرموز اللّغويـة ومن خلالهـ يستطيع الفرد التعبير عن الأفكار والمشـاعر وفهم مشاعر الآخرين الذين يستخدمون الرموز اللغويّة، وأيّ خلل فيه يعدّ عيبًا في الكلام. وبناءً على ذلك، تُعرَّف اضطرابات الكلام بأنها عدم القدرة على إصدار أصسوات اللغـة بصورة سليمة نتيجة لمشكلة في التناسق العضلي، أو عيب في مخارج أصوات الحروف، أو فقر في الكفاءة الصوتية، أو خلل عضوي، ولكي يتم التعرف إلى هذه الحالة وعدّها عيبًا أو اضطرابًا، فإنها يجب أن تعوق عملية التواصل، أو أن تسترعي اهتمام الثخص المتحدّث، أو أن تفضي إلى معاناة الفرد من القلق وسوء التوافق (بعيبع وزيدان، با ـ ب). وعليه تؤكد رجيعة (0 1 • r) أنّ اضطرابات الكلام ترتبط بعدد من سمات الثخصية التي يغلب عليها الطابع السلبي، مثل: تقدير الذات المنخفض، والعدوان، والشعور بالنقص، وحبّ العُزلة والانطواء المصحوب بالتوتّر النّفسي، والتحسّس من المشاركة في المواقف الاجتماعية، كما أنـه كثيرًا ما يصاحب اضطرابات الكلام أمراض نفسية، مثل: الخجل. 


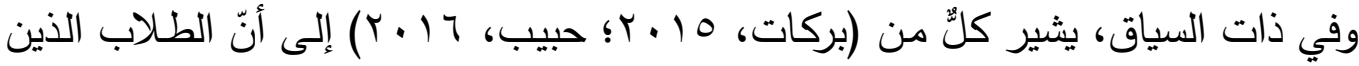
يعانون من اضطرابات الكلام يواجهون الكثير من الصعوبات الكلاميّة، وتظهر بشكل ملحوظ في المواقف التعليميّة المباشرة التي تستدعي قدرتهم على الكلام بصورة جيدة، وهذا بدوره يؤثِّر نفسيًّا في الطلاب مما يجعلهم يكوّنون مشاعر سلبية تجاه أنفسهم وتجاه الحياة وتجاه طريقتهم في الكلام.

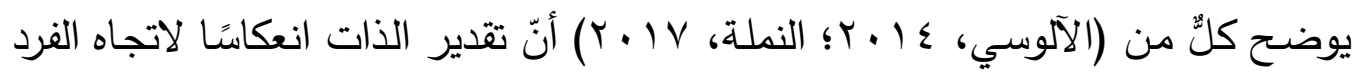
نحو نفسه، مثل أيّ من اتجاهاته الأخرى نحو موضوعات الحياة المختلفة، فالتصوّر الإيجابي للطالب عن ذاته يزيد من دافعيته، فكلّما ارتفع تقدير الذات ارتفع مستوى التحصيل الدراسي.

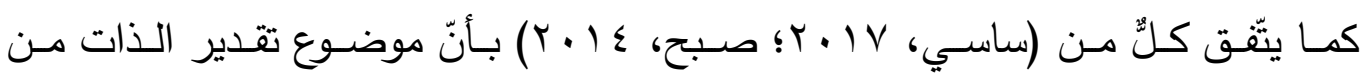

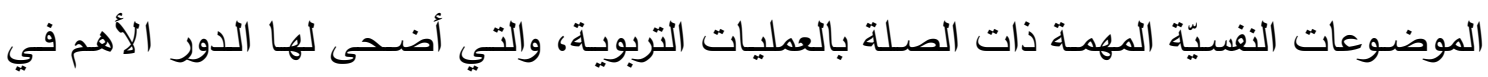
نجاح الطالب الجامعي أو إخفاقه، وفي ضـوء ذلك فإن هنـاك مجموعـة عوامل نفسية، وبيئية، واجتماعية، تؤثر في الدّراسة الجامعيّة، وبناءً على ذلك اهتم المختصّون في ميدان التربية وعلم

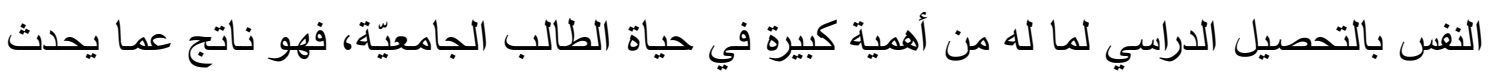

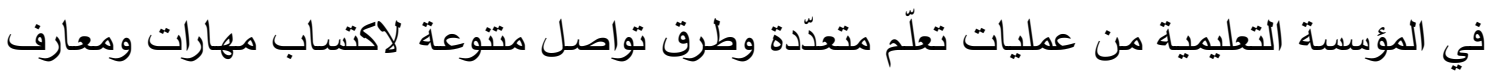
وعلوم مختلفـة بغرض تأهيل الكوادر البشريّة القادرة على العمل في المجـالات والاختصاصـات المختلفة، ونظير ما يصل إليه الطالب الجامعي من كفاءة تعلّم وتحقيق أفضل مستويات التحصيل الدراسي ستتحدّد مستقبلًا توجهاته المهنيّة.

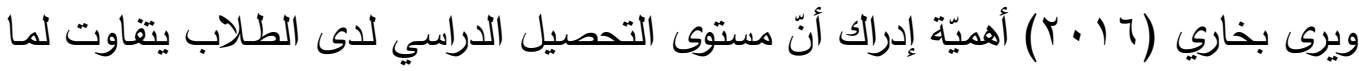
يعترض الموقف التعليمي من خبرات وعوامل إيجابية وسلبية ومثاكل ومواقف عديدة، والتي في مجملها لها تأثيرها الإيجابي أو السلبي على التحصيل الدراسي.

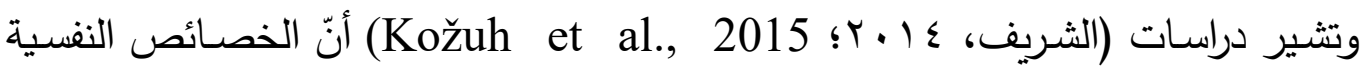
والاجتماعية للطالب هي عوامل بالغة التأثير على التحصيل الدراسي، ومن هذا المنطلق أوصى دأل الباحثون بضرورة الاهتمام بالطلبة من الجنسين ممن يعانون نقصًا في تقدير الذات لمساعدتهم على مواجهة الصعوبات والعوائق التي يجدونها في حياتهم الجامعية، لذلك سعى الباحثان لدراسة متغير تقدير الذات كونه من المتغيرات المهمة والمؤثرة على التحصيل الدراسي. 


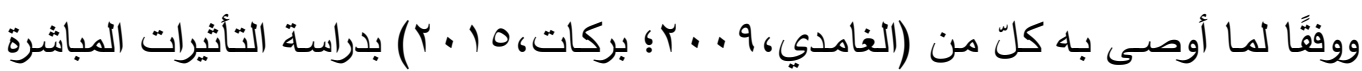
وغير المباشـرة لمشكلة اضطرابات الكـلام في مختلف مجالات الحياة، كالتعليم والعمل والزواج. وحيث إنّ الكفاءة الاجتماعيّة والتواصليّة والثقة بالنفس لدى الطالب ذوي اضطرابات الكلام محطّ للثك والرّبِة، ومن هذا المبدأ فإن التحصيل الدراسي يشكّل عبيًا نفسيَّا واجتماعيَّا لدى الكثير من طلبة الجامعـة ذوي اضطرابات الكعلام، لذلك سعى الباحثان لتطبيق البحث على طلبة المرحلة الجامعية ذوي اضطرابات الكلام، الجدير بالذكر أنّ المجتمع السعودي ما زال بحاجة ماسّة للكثير من الدّراسات في مجال اضطرابات الكلام في المراحل العمرية المختلفة، وهو ما يبرّر إجراء البحث الحالي في ضوء دراسة العلاقة الارتباطية بين تقدير الذات والتحصيل الدراسي لطلاب وطالبات المرحلة الجامعية الذين يعانون من اضطرابات الكلام.

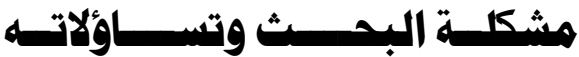

ظهرت مشكلة الدّراسة الحالية من خلال عمل الباحثان في جامعة جدّة، أثناء قيامهما بدروها التدريسي لاحظا وجود طلبة لديهم اضطراب في الكـلام، ويبدو عليهم عدم الارتياح داخل القاعة الدراسيّة، وبعد تقصّي الموضوع ومتابعتهم تبيّن أنهم يعانون من بعض المشكلات الأكاديمية، وفي ضوء ذلك كان من المهم التعرف إلى نتائج الذّراسات التي اهتمت بدراسة التحصيل الدراسي وعلاقته بتقدير الذات، حيث أشـارت نتائج الدراسـات التي اهتمت بدراسـة التحصيل الدراسي وعلاقته بتقدير

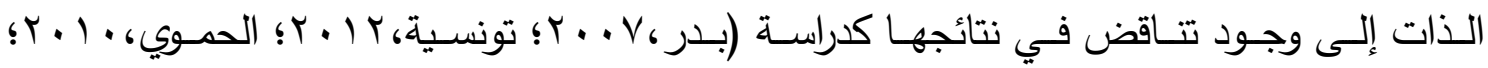

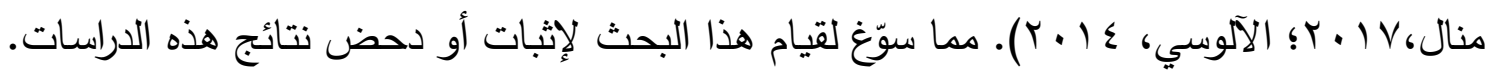
بالإضـافة لندرة الأبحاث بالمكتبة العربية التي اهتمت باضطرابات الكلام لتوجـه البحوث فيها على عينتي الأطفال والمراهقين، وهو مـا يبرر إجراء البحث الحالي خاصـة في ظل التركيز على عينة طلاب وطالبات المرحلة الجامعية ذوي اضطرابات الكلام، واستناداً إلى ذلك ظهر الإحساس بمشكلة

$$
\text { البحث الحالي، والتي تحددت في التساؤلات الآتية: }
$$

ما مستوى تقدير الذات لدى طلبة المرحلة الجامعية ذوي اضطرابات الكلاج؟ هل توجد علاقة ارتباطية بين تقدير الذات والتحصيل الدراسي لدى طلبة المرحلة الجامعية

$$
\text { ذوي اضطرابات الكلام؟ }
$$


هدف البحث الحالي إلى تحقيق الأهداف الآتية:

التعرف إلى مستوى تقدير الذات لدى طلبة المرحلة الجامعية ذوي اضطرابات الكلام. التعرف إلى علاقـة تقدير الذات والتحصيل الدراسي لدى طلبة المرحلـة الجامعيـة ذوي اضطرابات الكلام.

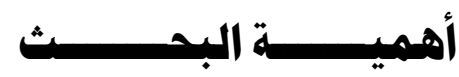

برزت أهمية البحث الحالي من خلال:

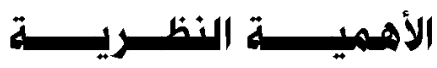

أ) أنـه يعتبر البحث الأول -على حد علم الباحثان-الذي يتــاول تقدير الذات وعلاقته بالتحصيل الدراسي لطلبة المرحلة الجامعية ذوي اضطرابات الكلام. ب) يتناول البحث التحصيل الدراسي لذوي اضطرابات الكلام كظاهرة تربوية-نفسية وتوضيح

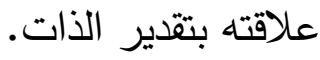

ج) تبرز أهمية البحث كونه موجه لطلاب وطالبات المرحلة الجامعية بإعتبارها مرحلة حساسة يتم فيها تأهيل الطلبة نفسيًا واجتماعيًا لضمان مشاركتهم الفاعلة في بناء المجتمع.

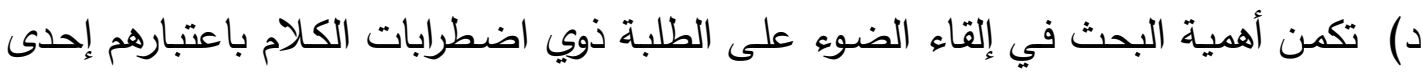
فئات التربية الخاصة التي لاتزال تحتاج إلى برامج وخدمات دعم تساهم في تحقيق التوافق النفسي والاجتماعي الذي يساعدهم في رفع مستوى التحصيل الدراسي.

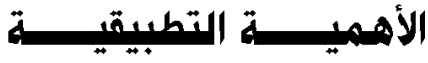

أ) من المأمول أن تكون نتائج البحث الحالي خطوة على الطريق الصحيح لتطوير برامج علاجية وإرشادية لرفع مستوى التحصيل الدراسي للى طلبة المرحلة الجامعية ذوي اضطرابات الكلام.

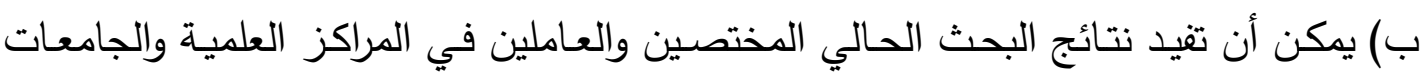
والمؤسسات ذات العلاقة في تقديم خدمات إرشادية نفسية لرفع مستوى تقدير الذات لاى الطلبة ذوي اضطرابات الكلام. 
ج) قد تقيد نتائج البحث الحالي الباحثين في مجال اضطرابات الكلام في صياغة تساؤلات

$$
\text { وفرضيات علمية لبحوث ودراسات مستقبلية. }
$$

د) يعزز أهمية هذا البحث التأكيد على جودة تعليم الطلاب ذوي الاحتياجات الخاصـة تحقيقًا

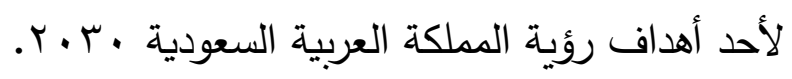

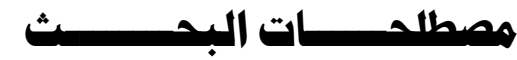

\section{تقديليـر الــات Self-Esteem}

يعرفه Cooper Smith "بأنه الحكم الذي يصدره الفرد على نفسـه متضمنًا الاتجاهات التي يرى أنها تصفه على نحو دقيق، ويقسم تعبير الفرد عن تقديره لذاته إلى قسمين: أولهما، التعبير الذاتي وهو إدراك الفرد لذاته ووصفه لها، والثاني، التعبير السلوكي، ويشير إلى الأساليب السلوكية التي تفصح عن تقدير الفرد لذاته، والتي تكون متاحة للملاحظة الخارجية" (النملة، V ا ـ Y، ص. مب). ويعرفه الباحثان إجرائيًا: هو الدرجة التي يحصل عليها المفحوص في استبانة تقدير الذات من إعداد الباحثان.

\section{:Academic Achievement التصيسـل الــدراسيسي}

"هو محصلة إجمالي نتائج المقررات الجامعية التي درسها الطالب في فصل دراسي واحد

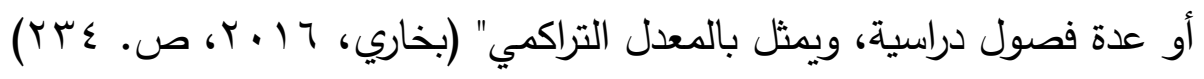

ويعرفه الباحثان إجرائيًا: هو أداء الطالب في نهاية الفصل الدراسي كما يتم قياسه بالمعدل

التراكمي (Grade Point Average GPA) حيث يعتبر مقياسًا ممثلاً لمستوى التحصيل الدراسي.

\section{اضطــرابـات الكـلام Speech Disorders:}

هو انحراف الكلام عن المدى المقبول في بيئة الفرد، وينظر إلى الكلام على أنه مضطرب

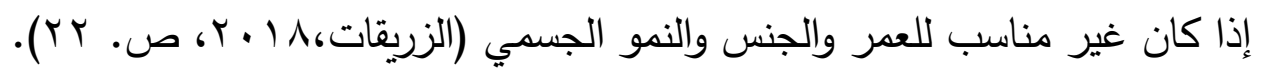

ويعرفها الباحثان إجرائيًا: بأنها مشكلات تتعلق بالإنتاج الثفوي للغة سواء في النطق أم الصوت

أم الطلاقة، والطلاب ذوي اضطرابات الكلام هم أولئك الذين يعيق كلامهم تواصلهم مع الآخرين. 


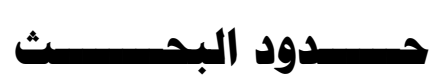

تم تطبيق البحث على عينة من الطلاب والطالبات ذوي اضطرابات الكلام في الجامعات

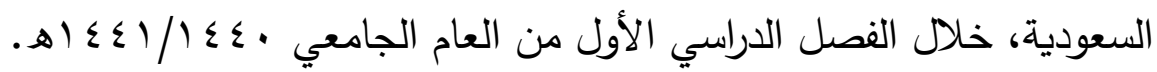

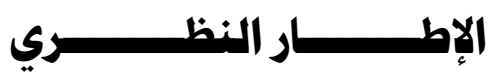

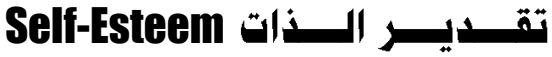

إنّ فكرة الفرد عن نفسه هي النواة الرئيسة التي تقوم عليها شخصيته، وتقدير الذات لا يولد مع الإنسان، بل هو مكتسب من تجاربه في الحياة وطريقة رد فعله تجاه التحديات والمشكلات في حياته، ومن الجدير بالذكر أن مفهوم تقدير الذات نابع من الحاجات الأساسية للإنسان، وتتضـح أهمية التقدير الإيجابي للذات حسب ماسلو Maslow في تنظيمه لهرمية الحاجات النفسية، حيث يرى أن هناك حاجة ماسة لتقدير الفرد لذاته واحترامـه لها والثقة بذاته، لأنّ الحاجة لتقدير الذات أو الشعور بالقيمة الذاتية هي في الواقع موجودة في أساس كلّ سلوك بشري، كما أوضح أن هناك حاجة ملحة لتقدير الذات من الآخرين، وتتجلى في رغبته أن يكون موضع تقدير من الآخرين وأن يعاملوه كثخص لله أهميته، حيث تشغل جانبًا كبيرًا من تفكيره، فهو بطبيعته يحتاج إلى المدح والتشجيع

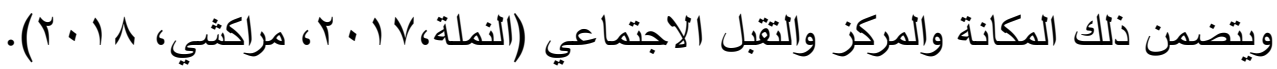

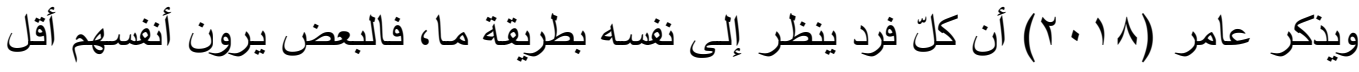
من الآخرين، وبالتالي ينعكس ذلك على سلوكهم، فهم لا يتصرفون بحماس وإقبال نحو غيرهم من الناس، والبعض الآخر يقدرون أنفسهم حق قدرها، وبالتالي ينعكس ذلك أيضًا على سلوكهم نحو غيرهم، فيتصرفون أفضل من غيرهم، ومن الجدير بالذكر أنّ فكرة الفرد عن ذاته منذ طفولته لا يقتصر تأثيرها على سلوكه الحالي، بل يمتد إلى سلوكه المستقبلي ويؤثر في تتميته الاجتماعية المقبلة حيث يميل ذوو تقدير الذات المرتفع إلى الحرية والاستقلال والابتكار والقدرة على التعبير عن آرائهم. ويشيـر كورك (Körük, 2017) إلى اهتمام العديد من الباحثين بتقدير الذات نظرًا لأثره الواضح في مختلف المراحل العمرية للفرد، كما أن هناك دراسات تشير إلى أن تقدير الذات للفرد يزداد كلما زاد العمر، فمع تقدم العمر يصبح لتقدير الذات دور مهم في مواجهة التغيرات والضغوط التي يمر بها الفرد أو يواجهها، ويوفر له القدرة والسيطرة على الصراعات التي تعترض حياته. 


\section{مفهـومر تثقـليـر الـذات}

لقد تعددت تعاريف تقدير الذات من قبل الباحثين والمهتمين بالدراسات النفسية، ويذكر الباحثان أهم هذه التعريفات:

حيث يعرفه روزنبيرج Rosenberg بأنه: "اتجاهات الفرد الثاملة نحو نفسـ، سالبة كانت

$$
\text { أم موجبة" (في: عسكر ، (99 (19، ص. 9). }
$$

أما قطب فأشارت بأنه: "كل ما يعطيه الفرد من تقديرات للصفات الحسنة والسيئة من حيث

$$
\text { درجة توافرها في ذاته أو مدى اعتزاز الفرد بذاته" (^99 (، ص. ـ اسب). }
$$

ويعرفه عبد الفتاح بأنه: "نظرة الفرد واتجاهه نحو ذاته، ومدى تقديره لها من الجوانب المختلفة

كالمركز الأسري والمهني وبقية الأدوار التي يمارسها في مجال العلاقة بالواقع" (ب99 (، ص.9بץ).

\section{مك موزنـات تثــليـر الــذات}

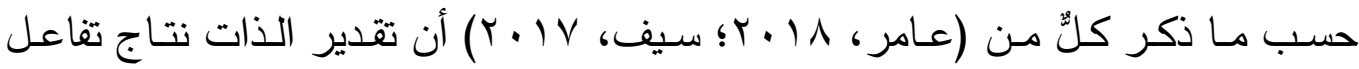

وتكامل ثلاثة مكونات أساسية، وهذه المكونات لا تعمل بمعزل عن بعضها البعض، أي أنّ هناك علاقة تفاعلية دائمة ومستمرة فيما بينهم، فحب الفرد لذاته يمكنّه من تكوين نظرة إيجابية حول ذاته، حيث تعدّ قوة داخلية تدفعه إلى أن يؤمن بقدراته، ويثق في ذاته، ويشعر بحرية التصرف دون خوف من الفشل ومن حكم الآخرين، ومكونات تقدير الذات هي كالآتي:

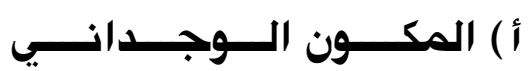

يعدّ حب الذات من أهم مكونات تقدير الذات، فهو يساعد الفرد في مواجهة الصعوبات التي

تعترضه في حياته ويحميه من الوقوع في اليأس، رغم إدراكه لنقائصه وحدوده، حيث يكون هذا الحب الذي يحمله الفرد لنفسه دون قيد ولا شرط، وتجدر الإشارة إلى أن حرمان الذات من هذا الحب يرجع أساسًا إلى مرحلة الطفولة مما يصعّب تداركه فيما بعد، فقد وجد أن الكثير من الأشخاص الذين يعانون حرمانًا في حبّهم لذواتهم يقعون عرضة لاضطرابات في الشخصية، ومن هنا يظهر أن حب الذات هو الركيزة الأولى لتقدير الذات. 


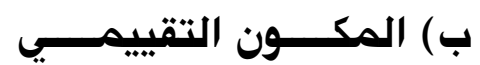

تعدّ النظرة للذات الركيزة الثانية لتقدير الذات، وهي تمثل تقييم الفرد لصفاته المختلفة

وإمكاناته، وقد يكون هذا التقييم إيجابيًّا أو سلبيَّا مبنيَّا على أسس حقيقية أو غير حقيقية، لذلك يظهر أنه من الصعب أن نفهم فهمًا صحيحًا النظرة إلى الذات لأن الذاتيّة تلعب دورًا كبيرًا فيها، وهذا ما يفّر الفرق بين نظرة الشخص المضطرب لذاته ونظرة الغير لله، حيث إنّ تقديره لذاته يكون ضعيفًا في الغالب لأنه يعتقد أنه يتصف بعيوب لا يدركها غيره.

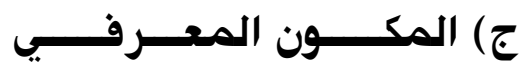

تثكِّل الثقة في الذات الركيزة الثالثة لتقدير الذات وهي خاصـة بأفعالنا وسلوكنا، فثقة الفرد بذاته تجعله يفكر بأنه يستطيع التصرف بطريقة مناسبة إزاء المواقف المهمة، وتجدر الإشارة إلى أنه يسهل الكثف عن ثقة الفرد بذاته لأنها تظهر جليَّا من خلال تصرفات الفرد عند تعرضه لمواقف غير متوقعة أو جديدة.

\section{أهميـة تثقـليـر الــذات للطـالب الجــامعي}

يثير عامر (1 ( • ب) إلى اهتمام كثير من العلماء والباحثين في شتى مجالات الدّراسات النفسية والتربويّة بمفهوم تقدير الذات، ويُعزى ذلك إلى أنه مرتبط بمجموعة من العوامل النفسية والتربويـة، كمـا أنـه من أهم المتغيرات التي تسـاعد في تحقيق الطالب لقدر مناسب من الصحة العقلية والنفسية والتوافق الاجتماعي والإنجاز والتحصيل الدراسي، حيث إنّ شعور الطالب بأنه ذو قيمـة ينمّي لديه الثقتة بالذات، ممـا يساعد في قدرته على مواجهة المشكلات وتخطّي الصساب وضغوط الحياة الجامعية التي يواجهها بإيجاد حلول توافقية مناسبة وتحقيق تحصيل دراسي جيد. (Jirdehi, Asgari, Tabari, وفي ذات السـياق، يذكر جيـردي، أصغري، طبري، وليلي (Leyli, 2018 أن تقدير الذات يمثل مفهومًا دُهمًا في العملية التعليمية، على اعتبار أن رؤيسة الطالب لذاته بصورة حسنة وتقديره لها تقديرًا إيجابيَّا يسهم في استتهاض قدراته وإمكاناته بما يحقّق بـه تحصيل دراسي مرتفع، فهي تمكنه من الثقة في قدراته والثعور بتقدير الذات والإحساس بالكفاءة عند إنجاز مهامه، وكل ذلك يمكّنه من السعي نحو التفوق والأفضلية، إضـافة إلى أن تقدير الذات يتطور عن طريق تتوع الخبرات والمواقف الحياتية التي يمر بها الطالب أثناء حياته الجامعية. 
وأكد كوبر سميث Cooper Smith أن تقدير الذات هو مفتاح النجاح ليس في التحصيل فقط ولكنه مفتاح النجاح في مواجهة مشكلات الحياة، حيث إنّ تأثيره عميق على جميع جوانب الحياة، فهو يؤثّر على مستوى الأداء في العمل، وعلى الطريقة التي يتفاعل بها الناس، وفي القدرة على التأثير في الآخرين، وعلى مستوى الصحة النفسية، كما أنّ الطلاب الناجحين يتسمون بارتفاع تقدير الذات والثقة بالنفس على عكس الطلاب المتعثرين دراسيًا، وأثتبت التّراسات أن هناك علاقة متبادلة بين تقدير الذات والتحصيل الدراسي، حيث إنّ ارتقاع تقدير الذات يزيد من مستوى التحصيل الدراسي، وفي الوقت نفسه

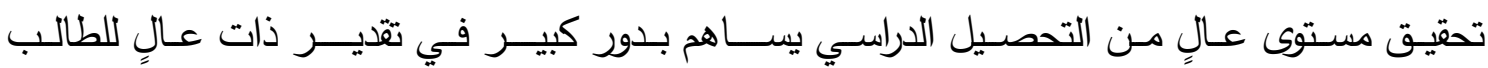
.(Körük, 2017 ؛ Cvencek, Fryberg, Covarrubias, \& Meltzoff, 2018) كما تئثّر اضطرابات الكلام على تقدير الذات لاى الطالب الجامعي، وتُضـعِف التحصيل الدراسي للطالب المصاب بها، وتؤثر على شخصيته واتجاهاته وذكائه وعلاقاته بالآخرين، حيث يعيش صراعًا بين الرغبة في التواصل مع الآخرين وتجنب اضطرابات الكلام، مما قد تكون سببًا في ضعف تقديره لذاته، وتولد مشاعر الدونيّة المصحوبة بالحذر، والقلق، والخجل، والغضب، وهو ما لـابل

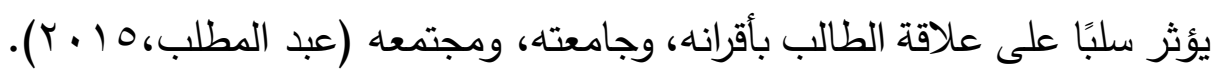

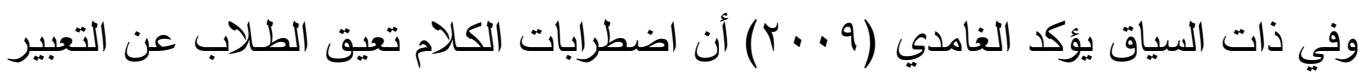
عن أنفهه والتواصل مع الآخرين، الأمر الذي قد يسهم في تدنّي مستوى تقدير الذات مما قد يؤدي بهم إلى الوقوع في العديد من الشككلات التي من بينها تجنب الاستماع لهم، وتجاهلهم، أو نبذهم والسخرية منهم بسبب صعوبة التواصل والتفاعل معهم، ويكون الحال أكثر صعوبة في المرحلة

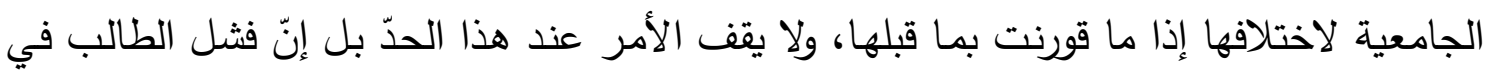
التواصل مع الآخرين يؤدي به إلى الوقوع في العديد من المشكلات النفسية والسلوكية نتيجة لها يعانيه من اضطرابات في الكلام.
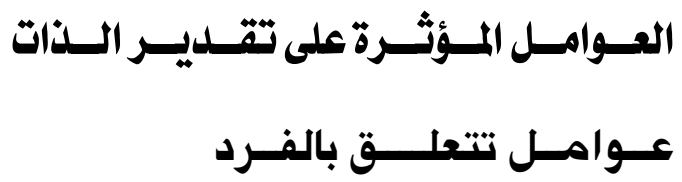

يذهب كامل إلى أنّ هنالك عوامل خاصـة بالفرد تئَّرّ في تقديره لذاته، منها: استعداداته

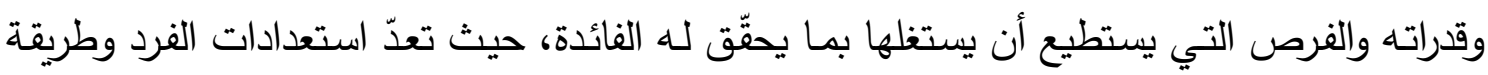


تعامله مع المواقف المحبطة عوامل مهمّة في تكوين تقدير الذات لديه، فالاستعدادات تؤهّل الفرد أن ييني إستراتيجيّات لمواجهة الضغوط بطريقة فاعلة دون التحقير من قيمة ذاته أو إهانتها (ع . . ب).

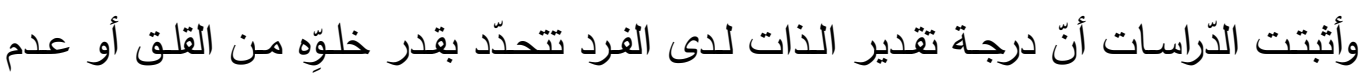
الاستقرار النفسي، بمعنى أنها إذا كان الفرد متمتِّعا بصحة نفسيّة جيدة يسـاعد ذلك على نموّه

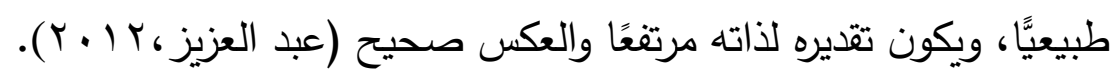
ويرى وولف Wolf أنّ العوامل الديناميّة الداخلية تلعب دورًا في تقدير الذات، ويشاطره الرأي أسعد (991 (191) الذي يرى أنه كلما كانت صورة الفرد الجسمية مشابهة للآخرين كلما كان تقديره لذاته مرتفعًا، في حين يساهم النمو العقلي الطبيعي والتفوق والابتكار في ارتفاع تقدير ذات

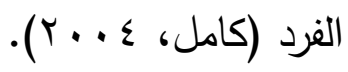

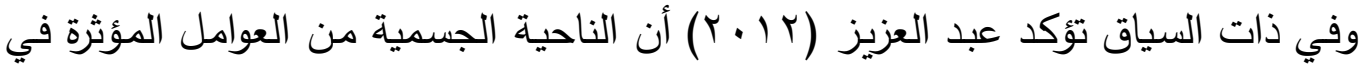
تقدير الذات، وتتضمّن بنية الجسم ومظهره وحجمه، فطول الجسم وتتاسقه ومظهره لها تأثير إيجابي في نظرة الفرد لذاته، لأنّ ذلك يدعوه إلى استجابات القبول والرضا، ومن الذّراسات التي أظهرت العلاقة بين تقدير الذات والنضج الجسمي دراسة (الظاهر ، • ( • ب).

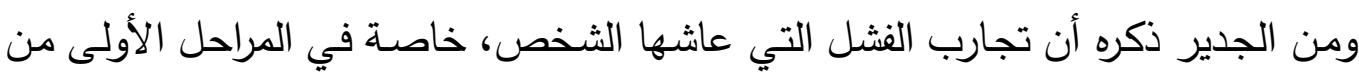
عمره، قد تكون اعتقادات خاطئة تبقى راسخة في ذهنه، ومصاحِبة له بقيّة حياته، مما يولّد لديه تقديرًا سلبيًّا، كما أنّ الملاحظات القاسية التي يوجّهها الآباء إلى الأبناء بسبب أخطائهم أو لعدم قدرتهم على تحقيق توقعات الكبار من شأنها أن تؤثر سلبًا على تقدير الذات وتكوّن لديهم حساسية مفرطة عند تعرّضهم لملاحظات الغير ، مما يزعزع ثقتهم بأنفسهم (ديب، عـ ( ب ب).

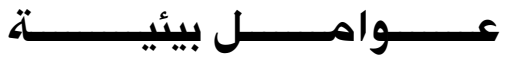

أ) الــر عـايـة الأسـريــة

تشير عبد العزيز (Y ( ب) إلى أنّ للتتشئة والخبرات التي يمر بها الفرد منذ طفولته المبكرة، والتجارب والخبرات الحياتية خلال فترة نموه، أثرها الكبير في تقديره لذاته، فكلما كانت التتشئة الاجتماعية

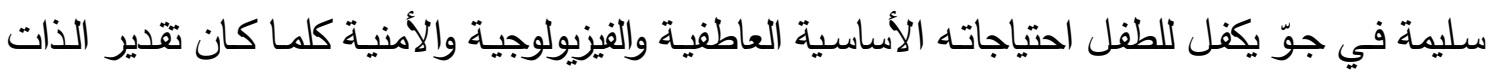
مرتفعًا، وانعكس نلك على شخصيّة الفزد في ثقته بنفسه التي تدفعه لتحقيق أهدافه في الحياة. 
كما بيّتت الدّراسات أنّ والدي الطلاب ذوي تقدير الذات المرتفع يشجعون السلوك المستقل لأبنـائهم واعتمـادهم على أنفسـهم، ويشـجعون على إبـداء آرائهم، أمـا والـدا الطـلاب ذوي التقدير المنخفض فـلا يقدّرون آراء أبنائهم ويحدّون من حريتهم ويكثرون من استخدام العقاب من منع وضرب وزجر ومعارضتهم على سلوكياتهم ونشاطهم الحرّ (اللحياني والعتيبي، 1 •r). فالأسرة تساهم في نمو تقدير الذات لدى الفرد من خلال عملية التعزيز والدعم التي بدورها تسمح للفرد القيام بالسلوك المرغوب فيه وتكراره، وبذلك يثعر بتقبل الآخرين لسلوكه، وبالتالي يشعر بثقته في نفسه واحترامه لذاته.

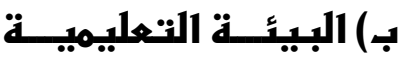

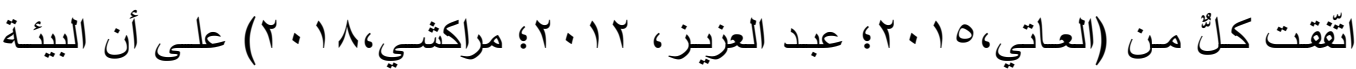
التعليمية تمثل عاملً مُهمًا في نشوء تقدير الذات للطالب، فبعد وضع الأسرة البذور الأولى لتكوين تقدير الذات يأتي دور المدرسـة لمـا تحتويـه من أفراد مُهمّين بالنسبة للطالب من معلمين وأقران، الذين يكون لهم الدور المكمل في نمو تقدير الذات للطالب، فحين يثي أشخاص ذو أهمية بالنسبة للفرد يزيد من تقديره لذاته. والأشخاص الذين يؤثّرون في تقدير الذات لدى الفرد في بيئته التعليمية:

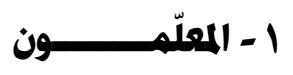

يلعب المعلمون دورًا مهمَّا في إشباع حاجة الفرد إلى التقدير ، وذلك بتقديم الثناء والتعزيز اللفظي والمادي لله لدى إنجازه الدراسي، أو الإبداعي أو العملي، فمن شأن كلّ ذلك أن يعزز ثقة الطالب بنفسه ورضاه عنها، وبالتالي فالطريقة التي يعتمدها المعلمون في الحكم على طلابهح وما تنطوي عليه من مدح أو ذم تلعب دورًا مهمَّا في تشكيل تقدير الذات لديهم، وقد تبيّن أنّ هنالك علاقة إيجابية متبادلة بين تقدير الذات وتقييمات المعلمين للطلاب.

\section{r- الــــــــــــ}

فالأصدقاء أحد العوامل المؤثرة في تقدير الذات خاصـة المراهقين، فالمراهق يحتاج إلى صداقات تشعره بأهميته، كما تتولد لديه الرغبة في أن يكون مثلهم، ففي المحيط المدرسي يكون الطلاب حسّاسين كثيرًا لإدراك قراتهم من طرف معلّميهم أو زملائهم، فرسائل الدعم والتشجيع والنصائح الموجهة إليهم تؤثر 
في تقييمهم لذواتهم وثتتهم في إمكانيتهم للتعلم، حيث نصت المفاهيم الحالية للدافعية نحو التعلم على أنّ الثقة في القدرات تتعلق بإنجازات الطالب الدراسية (التحصيل الدراسي).

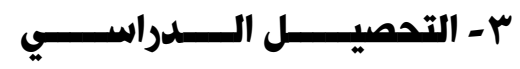

ثـة علاقة وثيقة بين تقدير الذات والتحصيل الدراسي، إذ يمكن القول إنه كلما زاد أحدهما أثر على الآخر إيجابًا، ولعل الدرجات التحصيلية أحد المقومات الأساسية لتقدير الذات لدى الطالب، فهي أحد المحكات الرئيسة لحسن ظنّه بقدراته، وتشير الدّراسات إلى أنّ الأفراد ذوي التحصيل المنخفض غالبًا ما يميلون إلى أن يكوّنوا مشاعر سلبيّة تجاه أنفسهم، في حين يميل الأفراد ذوو التحصيل المرتفع إلى تكوين مفاهيم ومشاعر إيجابيّة.

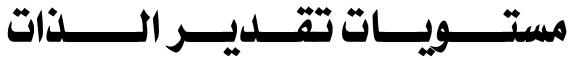

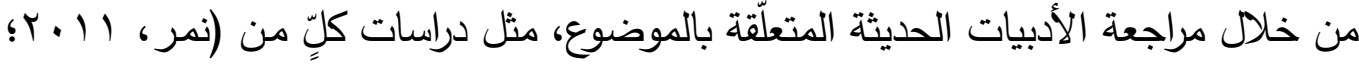

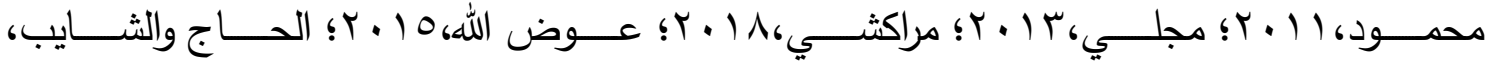
10

\section{أولاً: تقــــيـر الــذات المـرتفـــع} هذا المستوى يتضـمّن التقدير المرتفع والإيجابي للذات، وتحقيق التوافق النفسي للفرد، فالأفراد ذوو تقدير الذات المرتفع لديهم ثقة بأنفسهم واحترام لذواتهم، ويفتخرون بإنجازاتهم ويكونون على وعي جيّ بقدراتهم ومشاعرهم وانفعالاتهم، كما أنهم قادرون على تحمّل المسؤولية ويستطيعون إدراك الخطأ والتعامل مع النقد ومواجهته، ولديهج الرغبة في التغيير دون الثعور بأية دفاعات أو رفض للتغيير والطلاب الذين لديهم تقدير ذات عالٍ يعبّرون عن آرائهم ورغباتهم، وينخرطون بسهولة مع

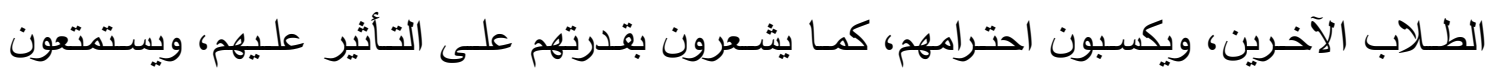
بالخبرات الجديدة، وكثيرًا ما يستخدمون إمكاناتهم لتحقيق أهدافهم، ويستجيبون للتحدّيات بإيجابية، كما تمكّنهم نظرتهم الإيجابية لذواتهم من تحقيق إنجاز أكاديمي وتحصيل دراسي مرتفع، بالإضافة إلى أن نظرتهم تفاؤليّة للمستقبل. 
هذا المستوى يتضـمن عدم تقدير الذات والتقليل من احترامها، كمـا أنّه يتضـمن الشـعور بالدونيّة، وأنّ الفرد يجد نفسـه أقلّ قيمـة من الآخرين في جميع المهارات، فالأفراد الذين يتميزون بمستوى منخفض من تقدير الذات يفتقرون عمومًا إلى الثقة في أنفسهم، ولديهم شكوك حول قيمتها ومدى قبولها، لا يتحملون مسؤولية أعمالهم ويلقون باللوم على الآخرين بسبب أوجه القصور فيها. والطلاب الذين لديهم تقدير ذات منخفض لا يميلون إلى التعبير عن أنفسهم فهم قليلًا ما يبدون آراءهم، كما أنهم ينكرون إمكاناتهج، ويعدّ الطلاب ذوو التقدير المنخفض غير مهمين وغير محبوبين، ويشعرون أن الآخرين لا يقدّرونهم ويضـعون اللوم عليهم لفشلهم، كمـا أنّه لا يقيمون علاقات إيجابيّة مـع الآخرين مـع ميلهم إلى بنـاء صداقات مـع عدد محدود، كما تكون نظرتهم للمستقبل سوداوية، وغالبًا ما يصابون بخيبة أمل في دراستهم الجامعية. وتضيف حبيب (T ( r) مستوى ثالثًا لتقدير الذات، ويقع بين هذين النوعين من الصفات وهو تقدير الذات المتوسط، حيث يعدّ الأشخاص من هذا النوع مما يقعون بين تقدير الذات المرتفع وتقدير الذات المنخفض، ويتحدّد تقدير الذات لديهم من قدرتهم على عمل الأشياء المطلوبة.

\section{Academic Achievement التحصيـــل الــدراسـي}

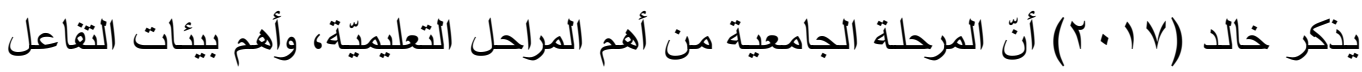
الاجتماعي للطلبة، حيث تلعب دورًا أساسيًّا في تحقيق الأهداف التي يصبو إليها أي مجتمع وفقًا لما يحتاجه من طاقات وخبرات ومهارات، ويعدّ التحصيل الدراسي من الأهداف السامية التي تسعى المجتمعات إلى تحقيقها من خلال برامج التربية والتعليم، وهو المؤشر الأساسي لمعرفة مدى نجاح العملية التعليمية، فالتحصيل الدراسي له أثر مباشر على الطالب لأن يمارس أية وظيفة تسند إليه دون الوقوع في أي قصور أو ضعف في التكوين أو الأداء.

يـولي الدارسون (Körük, 2017)؛ (Bahrami, \& Bahrami, 2015)؛

Zaidi \& Mahmood, 2015) إنجاز الطالب في المحيط التعليمي، والتركيز على المؤثرات الشخصية المتعلقة بالطالب كالسمات 
الثخصية المميزة، كما تؤكّد الدّراسات أن العوامل النفسية عامل حاسم في الرفع من مستوى التحصيل الدراسي لاى الطلاب، لذا اهتم المختصون في ميدان التربية وعلم النفس بالتحصيل الدراسي باعتباره ظاهرة تربوية- نفسية.

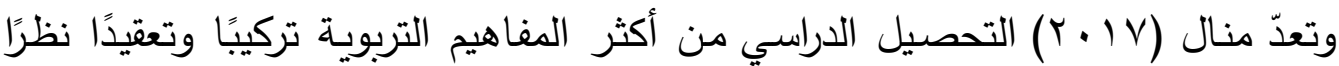
لارتباطه بالعديد من المتغيرات النفسية والاجتماعية، وبخاصة تقدير الذات، كما أنّ التحصيل الدراسي يلعب دورًا مهمًا في صنح الحياة اليومية للفرد، فهو نِتاج محسوس ومؤشر مهم للنجاح أو ولئي الفشل بالنسبة للفرد في المهام التي يقوم بها.

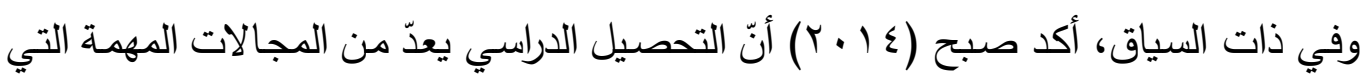
حظيت باهتمام الآباء والمربين، باعتباره أحد الأهداف التربويـة التي تسعى إلى تزويد الفرد بالعلوم

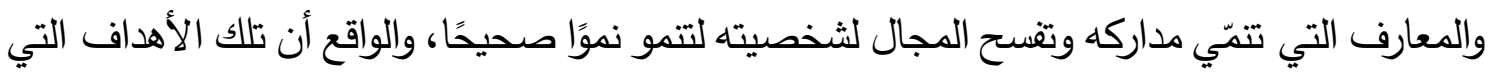
يسعى إليها النظام التعليمي تتعدى إلى ما هو أبعد من ذلك وهو غرس القيم الإيجابية وتربية الثعوب.

\section{مفهـــوم التحصيـل الـلدراسي}

تعرف سالم التحصيل الدراسي بأنه: "المعدل التراكمي الفصلي لمختلف المقررات الدراسية

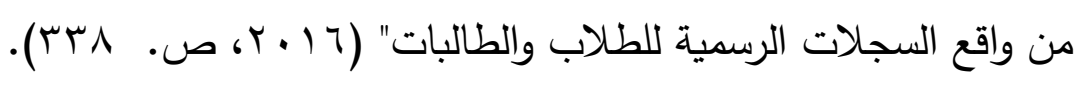

كما يشير بخاري (T ( ب ب) بأنه: "محصلة إجمالي نتائج الدقررات الدراسية التي درسها الطالب

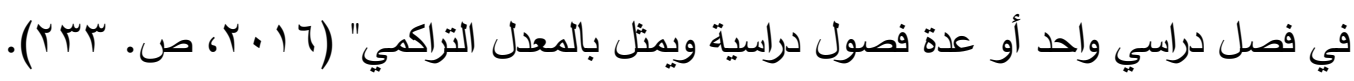
وفي المقابل يرى العيسوي أنه: مقدار المعرفة أو المهارة التي حصل عليها وليدا الفرد نتيجة

$$
\text { للتدريب والمرور بالخبرات السابقة (العيسوي، ... ؟ ب). }
$$

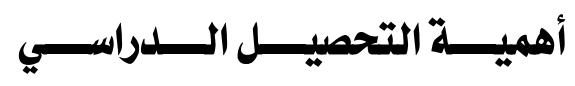

أشارت تونسية (r ( • ب) إلى أنّ التحصيل الدراسي من الظواهر التي شغلت فكر الكثير من التربويين، لما له من أهميّة في حياة الطلاب والأسرة والمجتمع، فالتحصيل الدراسي يقود إلى تحقيق لـقيق التقدم في مختلف المجالات، وتضيف أن التحصيل الدراسي يحظى بالاهتمام المتزايد من قبل ذوي الصلة بالنظام التعليمي لأنه أحد المعايير المهمة في تقويم تعليم الطلاب في المستويات التعليمية 
المختلفة، كما يعمل التحصيل الدراسي على تحقيق التقدم العلمي، فإن المجتمعات تستمد قوتها مما توفّره مخرجات التعلم بأنواعها، فـإن هذه المخرجات تقاس في إنجازهـا وكفاءتها بمقيـاس يسـى التحصيل الدراسي.

ولا شكّّ أنّ التحصيل الدراسي له أهمية كبيرة على مستوى الفرد وأسرته، فهو ليس فقط تجاوز مراحل دراسية متتالية بنجاح، بل له جوانب مهمّة جدَّا في حياة الفرد باعتباره تحديد مصير لاختيار نوع الدّراسة والمهنة، وبالتالي تحديد الدور الاجتماعي الذي سيقوم به الفرد، والمكانة الاجتماعية التي سيحققها، وشعوره بالنجاح ومستوى طموحه، كما أنهائهودي لإشباع حاجة من الحاجات النفسية للطالب وتحقيق التوافق النفسي، ونظرته الإيجابية لذاته (أحمد، • ( • ب).

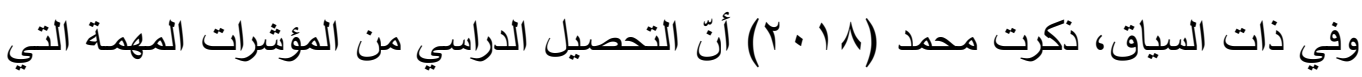
تؤثر في حياة الفرد وتتمّي قدراته العقلية مما يعمل على الانسجام بين سلولك الفرد وانفعالاته والذي يظهر أثره في درجة تحصيله الدراسي، ومما لا شكّ فيه أن التحصيل الدراسي لله أثر كبير في شخصية الطالب، إذ يجعل الطالب يتعرّف إلى قدراته وإمكاناته، كما يساعده في معرفة نقاط القوة والضعف لدياه، فوصوله إلى مستوى تحصيلي مناسب يبثّ في نفسه الثقة ويعزز قدراته ويدعوه إلى المواصلة والمثابرة، والعكس بالنسبة لفثله. وتكمن أهميّة التحصيل الدراسي في العملية التعليمية في كونها معيارًا لقياس مدى كفاءة العملية التعليمية ومؤشرًا لنجاح الطالب في الحياة الجامعية وفي الحياة اليومية، والقدرة على التفاعل والتعايش مـع الآخرين في المستقبل، كما أنّ الجامعات تعدّ المعدل التراكمي الذي يحصل عليه الطالب مقياسًا لقدراته (خالد، V V • (Y).

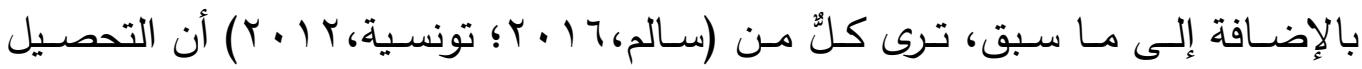
الدراسي يلعب دورًا أساسيًّا في استمرار عملية التعلم في جميع المراحل التعليمية، ففي المجال التربوي يعدّ التحصيل الدراسي المعيار الوحيد الذي يتم بموجبه قياس تقدم الطلبة في الدّراسة ونقلهم من صف تعليمي لآخر، بالإضـافة إلى أنه العامل الحاسم في تحديد التخصصـات التي يطمح إليها الطلاب وأسرهم، وذلك لما تعكسه هذه التخصصسات من مكانة اجتماعية واقتصسادية، كما ويعدّ التحصيل الدراسي للطالب من أهم المحكّات التي يتوقف عليها مستقبله في قبولهم في كليات 
وجامعات التعليم العالي، لذلك يهتم علماء التربية وغيرهم من المعنيين بالتعليم والتحصيل الدراسي اهتمامًا كبيرًا نظرًا لأهميته في حياة الفرد لما يترتب على نتائجه من قرارات تربوية حاسمة.

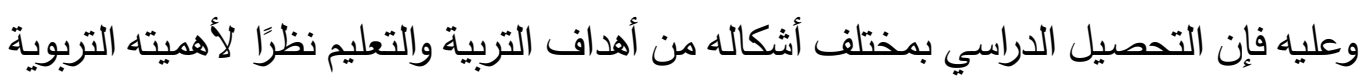
في حياة المتعلم، وفي مجال الحياة اليومية للتحصيل الدراسي أهمية كبيرة في تكيّف الطالب في الحياة ومواجهة مشكلاتها الذي قد يتمثل في استخدام الطالب حصيلة معارفه في التفكير وحلّ الشككلات التي تواجهه أو اتخاذ القرارات.

\section{أنـــــواع التحصيــل الــدراسـيـي}

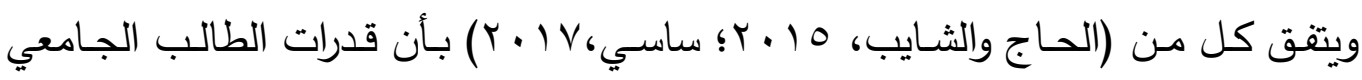

تتمثل في قدرته على التحصيل الدراسي وفق ثلاثة مستويات هي كالآتي:

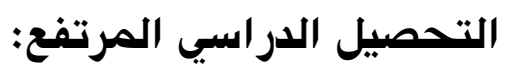

هو تجاوز الفرد في أداءه المستوى المتوقع منه في ضوء قدراته واستعداداته الخاصة، كما يكون أداؤه مرتفعًا عن معدل زملائه في نفس المستوى الجامعي وفي نفس القسم، وذلك باستخدام جميع القدرات والإمكانيات التي تكفل للطالب الحصول على مستوى تحصيل أعلى من خلال تأثير بعض المتغيرات المتمثلة في المثابرة، ارتفاع دافع الإنجاز لديه، والاستقراء الانفعالي والنفسي.

\section{التحصيل الدراسي المتوسط:}

في هذا النوع من التحصيل تكون الدرجة التي يتحصل عليها الطالب تمثل نصف

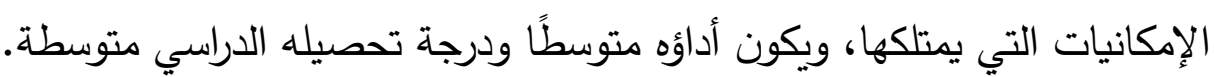
التحصيل الدر اسي الضعيف: يعرف هذا النوع من الأداء بالتحصيل الدراسي المنخفض، وهو عدم التوافق في الأداء عند المتعلم بين ما هو متوقع وبين ما ينجزه فعلاً من خلال تحصيله الدراسي، حيث يكون فيه أداء الطالب الجامعي أقل من المستوى العادي بالمقارنة مع بقية زملائه، فنسبة استغلاله واستفادته مما تقدم من المقرر الجامعي ضعيفة إلى درجة الانعدام، وسبب ذلك يعود لأحد العوامل المؤثرة على بلى بلى

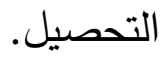




\section{العـوامـل المـؤثرة في التحصيـل الــدراسي}

يعدّ التّحصيل الدراسي المعيار الأساسي لمعرفة مدى تحقيق الطالب للأهداف التربوية، فقد اهتم التربويّون بموضوع التحصيل الدراسي وطرق تحسينه، والتحكّم في العوامل التي قد تؤثّر فيه أو تعيق عملية التعليم والتعلّم، ومن بين أهم العوامل المؤثرة في التحصيل الدراسي:

\section{أولاً: العـوامـل الخــاصـة بـالطـالـب}

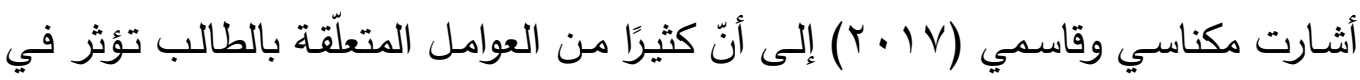

تحصيله الدراسي كوضعه الصحي من حيث سلامة الحواس (السمع، البصر )، أو أن يكون مصابًا بمشكلات جسدية أو أمراض مزمنة تؤثر في تحصيله الدراسي.

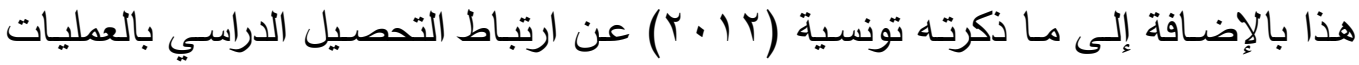
العقليـة كـالإدرالك والانتبـاه والتفكير والـذكاء والتـذكّر ، والاستيعاب والقدرة على الـربط والتحليـل والاستتناج، التي لها أهميـة بالغة في عملية التعلم، فكلّما زادت قدرة الطالب العقلية زادت درجـة التحصيل الدراسي لديه، وذلك يعني أن المهارات الفكريّة التي يتمتع بها الطالب تسـاعده في التحصيل، وحدوث أي خلل بها يؤدي إلى انخفاض مستوى التحصيل الدراسي.

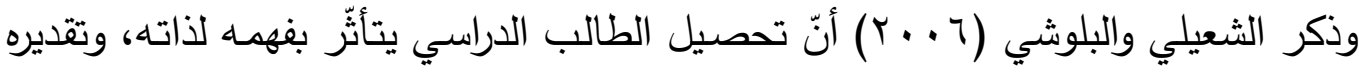
لها، وتؤكّد بعض البحوث أنّ الطالب الذي لديه مستوى عالٍ وإيجابي من تقدير الذات غالبًا يكون مستوى تحصيله الدراسي مرتفعًا، حيث يرتبط ذلك بنظرته الإيجابيّة لذاته وثقته بما لديه من إمكانات واستعدادات وقدرات وشعوره بالقدرة على النجاح وتخطِّي العقبات، وعلى العكس أيضًا فإن التحصيل الدراسي المرتفع بما يحقّقه من شعور بالنجاح والتقوّق والمكانة الاجتماعية يعزّز أيضًا المفهوم الإيجابي للذات، ويساهم في رفع مستوى تقدير الطالب لذاته. كما أوضحت عاشور (10 ب ب) العوامل المتعلقة برغبة الطالب في العلم من حيث درجة دافعيته وتعلّمه الذاتي، وكذلك مثابرته واجتهاده، كما تئتّرّ اتجاهات الطالب في تحصيله، سواءً أكان ذلك في اتجاهه نحو بيئته الجامعية، أم نحو المواد التي يدرسها، حيث توصلت الدّراسات إلى

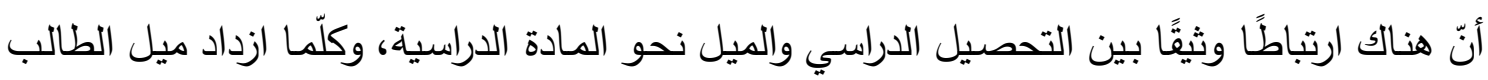


نحو المادة الدراسية تفوَّق وازداد تحصيله الدراسي فيها وتمايز عن غيره وساعد على بقاء أثر التعلم في هذه المواد، وكلما قلّ ميله نقص تحصيله فيها. كما كثفت الدّراسات العلمية عن وجود علاقة ارتباطيّة موجبة بين التحصيل الدراسي ووضع الأسرة، فالاستقرار الأسرى له أثر واضـح على التحصيل الدراسي للطالب، وأيضًا مركز الأسرة الاجتماعي والاقتصادي والثتافي يؤثر في التحصيل الدراسي، بالإضـافة لأهمية المستوى التعليمي للوالدين، حيث إنّه عامل مؤثّر في التحصيل الدراسي للأبناء (تونسية، ب ا ب ب). وقد ينخفض التحصيل الدراسي لدى الطلاب ذوي اضطرابات الكلام، ولا يفسّر ذلك بانخفاض الذكاء، ولكن يفسّــر بسبب ارتباط اضطرابات الكلام بالعديد من عوامل الخطر، مثـل: تدنّي تقدير الذات، والخـوف مـن التتيـيم السلبي، والإحـراج الاجتمـاعي ممــــــؤدي إلـى انخفـــاض التحصيــل الدراسسي (Hudson \& Rapee, 2009; Bloodstein \& Bernstein- Ratner,2008). (Blood \& Blood, 2016; Iverach, Rapee, وقد بيّنت نتائج دراســات كلٍ من Wong, \& Lowe, 2017 Iverach \& Rapee, 2014;) وتأثيره السلبي على حياة الطلاب المصابين باضطرابات الكلام، ويعدّ التكيف الاجتماعي السلبي الذي يعيشه الطلاب ذوو اضطرابات الكلام عاملًا خطرًا لتطوّر اضطراب القلق الاجتماعي، حيث أكدت الأبحاث أن التجارب السلبية التي يمر بها الطلاب ذوو اضطرابات الكلام غالبًا ما تتفاقم بسبب سخرية الزملاء، والتنّّر ، وضعف التحصيل الدراسي، كما تظهر لديهم اضطرابات المزاج واضطرابات الثخصيّة في الحالات الأكثر خطورة.
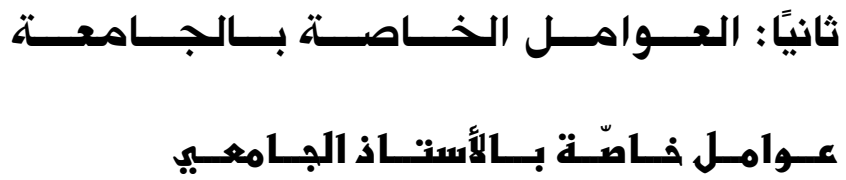

إنّ إعداد وتدريب الأسـاتذة مطلب حيوي لمواجهة تحدّيات الحاضر والمستقبل بمختلف أشكالها، وحيث إنّ جودة مخرجات التعليم تعتمد بدرجة كبيرة على الأستاذ وكيفية إعداده وتأهيله، وهي أحد معايير الحكم على نجاح الأستاذ الجامعي وكفاءته والثقة به. 
ومن هذا المنطلق يثير الحريري (· ( • ( إلى الكفاءات الضرورية للأستاذ الجامعي، وتشمل: • الكفاءة المعرفيّة: وتتضمن المهارات المعرفيّة والتخصّصية وربط التدريس بمتطلبات العمل والسعي إلى التطوير الدائم، وذلك من خلال إتقان المادة العلمية ومتابعة ما يستجد في مجال التخصص. • الكفاءة النفسية والاجتماعية: وتتضمّن الصحة النفيّة ومقوّماتها، مما يساعد على القدرة على تحمل الضغوط والتكيف مع المتغيرات المتلاحقة. • الكفـاءة المهنيّة: وتشتمل على المهارات الفنيـة المتخصصـة والالتزام بأخلاقيات المهنـة، وامتلاك ثقافة الإبداع والإنجاز والبناء والمشاركة. • الهوية والانتماء: وهي وضوح الهوية وقوة الانتماء والشعور بالمواطنة والاعتزاز بالوطن. عــوامـل فـاصـة بـالمنهــــ أهداف المنهج ومـا يتّصل بها من حيث تنوّعها، وشمولها المجالات المعرفيـة والوجدانيـة والمهاريّة، وصـلتها بحاجـات المجتمع والطـلاب ومـا يتعلق بقدراتهم وميولهم، ومواكبتهـا للتطور العلمي والتكنولوجي. بالإضـافة لطرق التدريس وأسـاليبها من حيث ملاءمتها للموضـوعات وأهداف التدريس، وظروف الموقف التعليمي، وتتوّعها وتوظيف الوسائل التعليمية وإمكانية استخدامها، كما أنّ سوء اختيار الطريقة المناسبة لتدريس أي موضوع دراسي يؤثر في التحصيل الدراسي للطلاب، ويحول

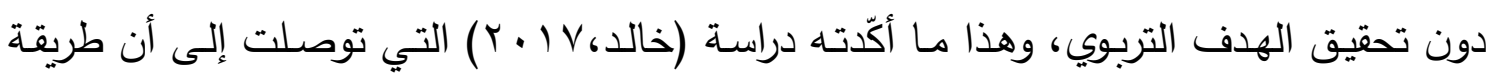
الأسـتاذ في التـدريس وسـلوكه في التعامـل مـع طلابـهـ مـن أهـم العوامـل المـؤثرة في التحصـيل

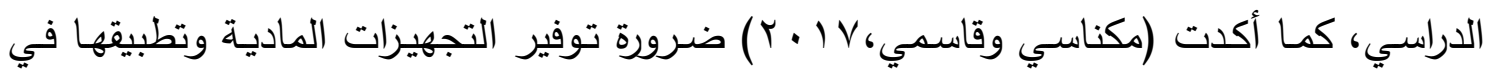
ظروف ملائكـة، حيث إنّ صـلاحيتها، وكفايتها، واستجابتها لمتطلبات تنفيذ المنهج من عوامل نجاح المنهج أو فثله.

\section{عــوامـل فـاصــة بـالاضنتبــارات} يمكن الاستـلال على قدرات الطلاب المعرفية والمهاريـة من خلال الاختبارات، على الرغم أنها غالبًا لا تعطي الصورة الحقيقية أو الكاملة عن الطالب، وهي عرضة للنقد لأنها تقيس مستويات 

معيّنة فقط من القدرات العقلية في الوقت الذي يمتلك العقل البشري إمكانات هائلة وكثيرًا ما يرجح طلبة المرحلة الجامعية تدني تحصيلهم الدراسي إلى طبيعة الاختبار (الثعيلي والبلوشي، ج · . ب).

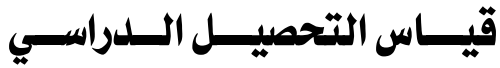
تعدّ الاختبارات التحصيلية التي يراد بها قياس التحصيل الدراسي من أهم وسـئل تقويم التحصيل الدراسي، وتحديد مدى تحقيق الطلاب للأهداف التعليمية في مقرّ معين أو في مجموعة من المقررات الدراسيّة، وهـي قديمـة قِدَم المعـارف والعلوم المختلفـة، حيث ارتبطت دومًا بـالتعليم وبمعرفـة نتائجهاه، وهناك أنواع من الاختبارات التحصيلية التي يمكن استخدامها، منها: التحريريـة والثفهية، الموضوعية، والمقالية، العملية والمعيارية (تونسية، ب ( • ب).

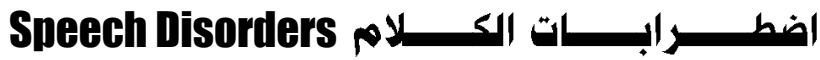

من المعلوم أنّ الناس يتفاوتون فيما يملكون من قدرات على تحقيق مطالبهم وحاجاتهم الحياتية، ومن هذه القدرات: القدرة على التواصل، والكفاية اللغويـة التواصلية، وتؤثر سمات الفرد الثخصية في قدرته على تحقيق التواصل مع غيره، ولذا فإن من يمتلك صحة نفسية جيدة يمتلك بالضرورة قدرة على التفاهم الجيّد مع واقعـه الخارجي، ذلك أن مهارات التواصل ترتبط بعوالم النفس البشرية ارتباطًا وثيقًا، ومن ثم فإنّ إتقان هذه المهارات يمثل أهمية بالغة في إصلاح النفس، وتهذيبها، وترتيب مداركها، وتتسيق طباعها (إبراهيم، I ( • ب). وتذكُر عبد الله (V V · r أنّ موضوع الكلام من الموضوعات المهمة التي شغلت القدماء والمحدثين من علماء اللغة والكلام والطبّ وعلم النفس وعلماء الاجتماع والتربية وغيرهم من العلماء في مجالات التخصصات المختلفة، حيث إنّ الكلام من أهم سبل الاتصال النفسي بين الفرد والفرد الآخر ، فإذا تكلَّم شخص فإنه ينقل حالات نفسية كاملة تحمل معاني ومشاعر وانفعالات وأفكار . ولهذا أكد هؤلاء الباحثون على أهمية الكـلام في القدرة على التواصل وتأثيره على النمو العقلي والفكري والاجتماعي والنفسي.

ويعرف الزريقات (1 ( • ب) الكلام بأنه: وسط التواصل الفهي الذي يستخدم الرموز الصوتيّة ومن خلاله يستطيع الفرد أن يعبّر عن أفكاره ومشاعره وأن يفهم مشاعر الآخرين الذين يستخدمون الرموز اللغوية، وهو نشاط حركي للتنفس والتصويت والنطق والرنين الصوتي. 
ويعدّ الكلام أكثر الأنشطة تعقيدًا وأهم الأنشطة العضلية توازنًا، كما أنه يتطلب تتاسقًا تامًا فيما بينهم، ونظرًا لطبيعته المعقدة ومناطقه العصبية ومجموعاته العضلية التي لا حصر لها، فإن كلام الفرد يكون عرضة للمشكلات، كما يمكن أن يكون مضطربًا (عبد الله، V . Y). فـإن تعـرض الفـرد لأي خلـل عضــوي، أو مـؤثرات نفسـية، واجتماعيـة قــــــؤدي إلـى اضـطرابات الكـلام، ممـا يعنـي إعاقـة تواصـله مـع الآخـرين، وبالتـالي قد يتـأثر الفـرد جـراء هـذه الاضـرابات نفسيَّا، واجتماعيًا إلى الدرجـة التي تتطلب التدخل الطبي والنفسي لمسـاعدته في التعامل مع هذه الاضطرابات (الغامدي،9، . . ب). تظهر اضطرابات الكلام عند الأفراد من جميع الأعمار ، وتتراوح في حدتها اضطرابات خفيفة إلى بالغـة الحدّة، كما أنّ النتائج المترتبة على هذه الاضطرابات تتراوح في حدّتها أيضًا، علاوة على ذلك فإن اضطرابات الكلام يمكن أن توجد كمظهر فريد عند الشخص، وقد تكون جزءًا من صورة معقدة من الإعاقات المتعددة، كذلك يمكن أن تكون هذه الاضطرابات وقتية ولا تستمر طويلًا، كما أنها يمكن أن تبقى مع الفرد مدى الحياة (بركات، 1 .). وقد اتفق العديد من الباحثين على أن الأفراد المصابين باضطرابات الكلام تظهر عليهر الأعراض الآتية: انخفاض تقدير الذات، والانسحاب، والثـور بعدم الأمان، والخجل (شقير،

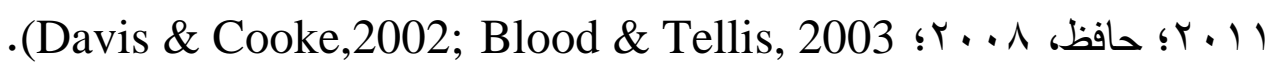

\section{مفهــومر اضطــــرابــات الـكلام}

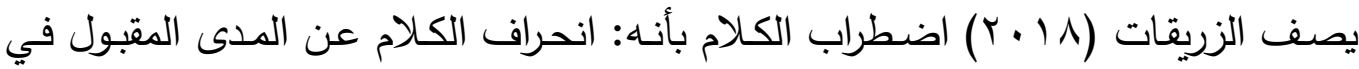
بيئة الفرد وينظر إلى الكلام على أنه مضطرب إذا اتصف بالخصـائص التالية: صعوبة سماعه، عدم وضـوحه، خصـائص صسوتية وبصسرية غير مناسبة، اضطرابات في إنتاج أصسوات محددة، إجهاد في إنتاج الأصـوات، عيوب في الإيقاع والكلام، عيوب لغويـة، كـلام غير مناسب للعمر وللجنس والنمو الجسمي.

وحسب الجمعية الأمريكية للنطق والسمع (ASHA) تعرف اضطرابات الكلام بأنها: خلل

في التعبير عن أصوات الكلام وهي: الطلاقة أو الصوت أو النطق (1993). 


\section{أسبــــاب اضطـــرابـــــات الـكلام}

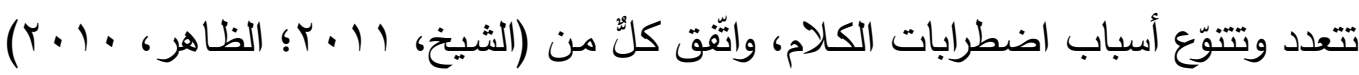

أن الأسباب العضوية أو النفسية أو البيئية والاجتماعية أو التعليمية أو الوظيفية هي أكثر الأسباب انتشارًا، وقد يشترك جانبان أو أكثر في الإصابة بهذه الاضطرابات، يذكر منها الباحثان الآتي:

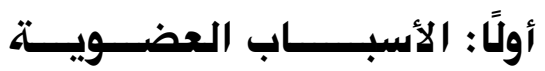

عملية الكـلام ليست سـهلة وإنما تحتاج إلى أعضـاء سليمة متعدّدة لكي يمارس الفرد الكـلام بثكل طبيعي، إذ يحتاج الكلام الطبيعي إلى جهاز تتفسي سليم وجهاز صوتي، وعصبي وأعضاء نطق سليمة كذلك، فمن الأسباب التي تؤدي إلى اضطرابات الكلام هي الإصـابة أو الخلل في أحد هذه الأجهزة، حيث تترك آثارًا سلبية على كلام الفرد، وتسبب صعوبات في الإرسال أو ممارسة الكلام.

\section{ثانيًا: الأسبــــاب النفسيــــتة}

وهي الأسباب الغالبة على معظم حالات عيوب الكلام، كما أنها تصاحب أغلب الحالات العضـوية، ومـن هذه الأسباب: عدم تقدير الـات، الاكتئـاب، عدم الثـعور بـالأمن والطمأنينة، المخاوف، الوساوس، الصدمات الانفعاليّة، الثعور بالنقص وعدم الكفاءة.

\section{ثالثًا: الأسبــاب البيئيـــة والاجتمــاعيّــة}

البيئة هي التي تشكل الملامح الأساسية لما سيكون عليه الفرد مستقبلًا، فهنالك من يعيش في بيُّة سـلبية بكل جوانبها، حيـث إنّ الظـروف الأسـرية غيـر السـويّة تـرتبط ارتباطـا مباشـرًا باضطرابات الكـلام، وهنـاك من يعيش في بيئة صـية سليمة، فأسـاليب التربية الواعيـة الصـحية والعلاقـة المثـرة المتفاعلـة بـين الآبـاء سـتلقي بظلالهـا الإيجابيّة على الأبنـاء، بالإضـافة إلى أن المستوى الاقتصـادي والاجتماعي وحجم الأسرة عوامل بالغة التأثير في كلام الفرد، كما أن وجود الفرد في بيئة تتعدد فيها اللغات واللهجات من وقت لآخر قد يشكل عائقًا في تواصله مع الآخرين.

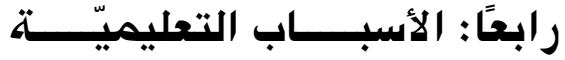

مهارات التواصل والكلام تمثل استجابات متعلمة عند الفرد، وبالتالي فإن هذه الاستجابات تصـبح مضـطربة عندما تكون أنمـاط التفاعل بين الفرد والآخرين في المحيط التعليمي أنماطًا 
مضطربة وغير إيجابية، كما أنّ للطرق والأسـاليب والفنيات التي يتبعها المعلم أهميتها في جعل الفرد متكيًِّا أو غير متكيف، فالأسـاليب غير التربويـة التي يتبعها المعلم مع الطلاب تتؤثر سلبًا على الطلبة، فالعقاب والخبرات غير السـارة والمقارنات المتكررة بين الطـلاب والإخفاق والرسوب المتكرر الذي يؤدي بالفرد أحيانًا إلى الانسحاب والانكفاء والعدوان للتنفيس عن الأنا الداخلية التي تعتريها من تعرّضه لمشكلات التعليم.

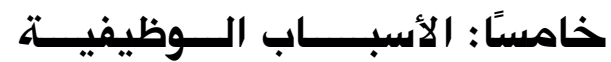
قـد تكـون الاضــرابات الكلاميـة ناجمـة عـن إســاءة اسـتخدام أجهـزة الكـلام، فالجهـاز البلعـومي يعـدّ مـن أكثر الأجهـزة تعرّضًا لإسـاءة الاسـتخدام، الأمـر الـذي يـؤدي أحيانَـا إلـى تلف عضوي في تلك الأجهزة.

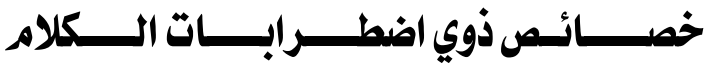

يشير الجزازي (11 (1) إلى أنّه على الرغم من أن اضطرابات الكلام كثيرة في أنواعها ومتفاوتة في درجاتها، ولكن بشكل عام توجد سمات مشتركة بين الأفراد ذوي اضطرابات الكلام وتتمثل هذه الخصائص في الآتي:

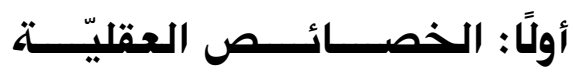

ويقصـد بهـا أداء المفحوص على اختبارات الذكاء المعروفـة، حيث إنّ ذوي اضـرابات الكلام لديهم تأنِّ في اللغة مقارنـة بأقرانهم في نفس الفئة العمريـة، الأمر الذي يؤدّي إلى تدنِّ في التحصيل الدراسي.

\section{ثانيًا: الخصائص النفسيتة والاجتماعيّة}

يوصف المصاب باضطرابات الكلام بمستويات عالية من القلق والتوتر وعدم الثقة بالنفس والإحباط والثعور بالذنب، وعدم تقدير الذات، كما أنّه يقوم بسلوكيّات غير تكيّفية كالسلوك العدواني والثعور بالرفض من قبل الآخرين، والانسحاب من المواقف الاجتماعية والثعور بالفشل. وقد تصدر هذه الاستجابات عن الفرد من ذوي الاضطرابات الكلامية بفعل اتجاهات الآخرين نحوه وتوقّاتهم منه، نتيجة لذللك فقد يعامل الفرد بطريقة مُبالَغ فيها من الحماية الزائدة أو الرفض والعزلة. 


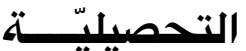

الدوافع هي المحرك الأساسي للتعلم وتكوِن لدى الطـلاب توجُهِا داخليَّا نحو التعلّم، فإذا شعر الأفراد الذين يعانون من صعوبات في الكلام بتوقعات منخفضة في الأداء الدراسي، هذا بدوره يضعف الدافعيّة نحو الدّراسة والتعلّم مما يؤدّي لتدنّي مستوى التحصيل الدراسي.

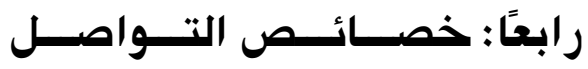

الأفراد ذوو اضطرابات الكلام يجدون صعوبة في التواصل مع الآخرين، لذلك فهم يخشون الآخرين ويتجنبّون الحديث معهم، خشية الانتقاد أو التعرض لمواقف محرجة، فبعضهم يعتقد عدم قدرة المستقبل على فهم ما يقصد ويجد صعوبة في التعبير عند الحديث.

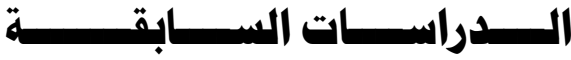

هدفت دراسة نورونها، مونتيرو، وبينتو (Noronha, Monteiro, \& Pinto, 2018)

لمعرفة مستوى تقدير الذات للطلاب ذوي الأداء الأكاديمي المنخفض، ومعرفة المستوى الاجتماعي والاقتصادي للطلاب، ومعرفة العلاقة بين تقدير الذات والأداء الأكاديمي والفروق بين الجنسين في مستوى تقدير الذات والأداء الأكاديمي. طبّقت الذّراسـة على عيّنة عشوائية تكونت من • م طالبًا

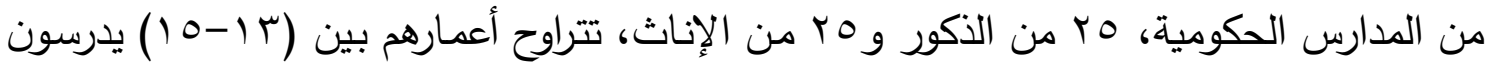

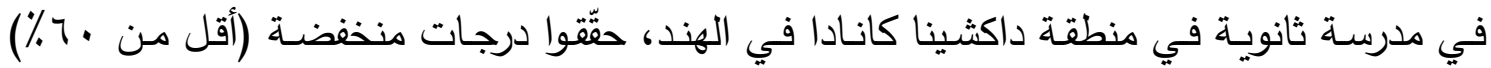
وفثلوا في واحد أو أكثر من المواد. استخدم الباحثون المنهج الوصفي، كما تم استخدام الاستبيان والمقابلة أدوات لتحقيق أهداف الدّراسة، كثفت النتائج عن وجود فروق بين الجنسين، حيث تتمتع الإناث بتقدير بالذات أكثر من الذكور ، وعدم وجود علاقة ذات دلالة إحصـئيّة بين تقدير الذات والتحصـيل الدراسـي، عـلاوة على ذلك، فـإن نظـام التعلـيم، والصــحة النفسية للطالب وأسـرته، وأصدقائه، والمدرسين له أهمية قصوى في تحديد مستوى التحصيل الدراسي للمراهق في المدرسة. ويوصسي الباحثون بوضـع برنـامج للتدخل للآبـاء والأمهات لمسـاعدة المراهقين على زيـادة تقديرهم لذاتهم وأدائهم الأكاديمي، كما يجب تقديم المساعدة للطلاب الذين يظهرون أداءً أكاديميًّا منخفضًا ومساعدتهم من قبل المعلمين، وأفراد الأسرة، والأقران، وإجراء المزيد من الدّراسات البحثية الطولية لعدد كبير من الناس وتكون أكثر فاعلية وتكثف عن الفروق في عيّنة حضريّة وريفية والفروق بين

$$
\text { المدارس والكليات الحكومية والخاصة. }
$$




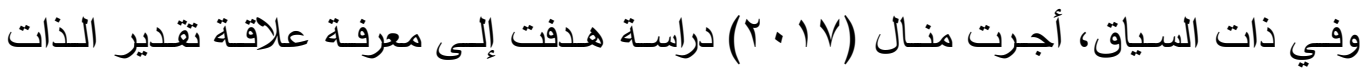
بالتحصيل الدراسي لاى تلاميذ المرحلة المتوسطة. اتبعت الباحثة المنهج الوصفي، بعد التعرُّف إلى متغيّرات الذّراسة والمتمثلة في: تقدير الذات، التحصيل الدراسي وخصسائص التلميذ الجسمية، النفسية والعقلية في مرحلة التعليم المتوسط. طبّتت الباحثة مقياس Cooper Smith لتقدير الذات على عيّنة من التلاميذ عددهم ،ه تلميذًا موزّعين على خمسة أقسام بمستويات مختلفة ذكورًا وإناثًا، ومن خلال النتائج المُتحصَّل عليها تم إثبات وجود علاقة بين تقدير الذات والتحصيل الدراسي لدى تلاميذ مرحلة التعليم المتوسط، فكلّما زاد تقدير الذات لديهح صـاحبته زيادة في التحصيل الدراسي، وكلما انخفض تقدير الذات لوحظ انخفاض في التحصيل الدراسي لديهم، وهذا ما يثبت صحة فرضية البحث بأن هناك علاقة قوية بين تقدير الذات والتحصيل الدراسي لدى تلاميذ التعليم المتوسط.

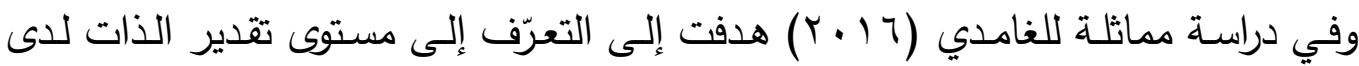
طلبة قسم التربية البدنية بجامعة أم القرى، وعلاقة تقدير ذاتهم بتحصيلهم الدراسي مقيسًا بالمعدل التراكمي. وتحقيقًا لأهداف الدّراسة استخدم الباحث المنهج الوصفي المسحي، وتم استخدام مقياس Rosenberg لتقدير الذات، وتطبيقـه على جميع طلبـة قسم التربية البدنيـة ممـن أكملـوا جميع متطلبـات السنة الدراسـية الرابعـة والأخيرة، وبلـغ عددهم بـا طالبًا. وأشـارت النتائج إلى وجـود مستوى مرتفع من تقدير الذات لدى الطلبة، وأن الطلبة أصحاب المعدلات التراكمية المرتفعة هم أكثر تقديرًا لذاتهم، وأوصى الباحث بناء على نتائج هذه الدّراسـة ونتائج الدّراسات المرتبطة بإجراء المزيـــ مـن الدّراسـات، حيـث إنّ إثبات العلاقـة بـين تقدير الـذات وممارسـة الرياضـات كالألعـاب المختلفـة واللياقـة البدنيـة، قد يـدفع أصـحاب القـرار في وزارة التعليم إلى إعـادة النظـر في عدد الحصص المخصصـة للتربية البدنية في مختلف مراحل التعليم العام، وإعادة طرح مقرر التربية البدنيـة لكلّ طلبة الجامعـة كمقرّر اختياري، بحيث يصـم بطريقة تسهم في زيـادة الوعي بأهميـة اللياقة والرياضة البدنية والحركة، بالإضـافة إلى مساعدة الطالب في اختيار الرياضـة التي تتناسب مع ميوله وقدراته. وخفض العبء الدراسي لطلاب الجامعة بالقدر الذي يمنحهم وقتًا كافيًا لممارسة المناشط الرياضية والحركية. 
كمـا تؤكـد دراسـة الحساج والثـايب (10 ب ب) العلاقـة بـين تقدير الـات الكلـي والرفــي

والمدرسي والعائلي والتحصيل الدراسي لدى تلاميذ السنة الرابعة متوسط، ومن أجل تحقيق أهداف الدّراسـة واختبار الفرضـيات قـام الباحثـان باتباع الخطوات والمبـادئ والقواعد الأساسية للمنهج الوصفي الذي يتناسب مع الدّراسة، طبّق الباحثان هذه الدّراسة على عيّنة مكونة من . . 1 تلميذ يدرسون بمستوى سنة رابعة متوسط والذين تم اختيارهم بطريقة عشوائية في ولاية ورقلة بالجزائر • وتم استخدام مقياس Bruss.R. Hair لتقدير الذات لجمع البيانات ومعالجتها باستخدام مجموعة من الأسـاليب الإحصـائية المناسبة، وقد أظهرت نتائج الذّراسـة وجود علاقة قويـة بين التحصيل الدراسي وكلّ من تقدير الذات الكلي والرفاقي والمدرسي والعائلي. وأثارت عوض الله (0 ( ب ) في دراستها إلى علاقة تقدير الذات بالتحصيل الدراسي لدى الأطفال المعاقين سمعيًا بمعاهد الأمل، وقد بلغت العيّنة ع من الطلاب والطالبات المعاقين سمعيًا، تم اختيارها بطريقة قصدية، تراوحت أعمارهم (Y ( - 10 سنة). اتبّعت الباحثة المنهج الوصفي، استخدمت فيه الباحثة مقياس Cooper Smith لتقدير الذات. وأهم النتائج التي توصلت إليها الباحثة: يتسم تقدير الذات لاى الأطفال المعاقين سمعيًّا بولاية الخرطوم بالارتفاع، توجد فروق دالة إحصائيًا بين الجنسين في تقدير الذات لدى الأطفال المعاقين سمعيًّ بولاية الخرطوم لصالح الذكور . كما توجد علاقة ارتباطية دالة إحصائيًا بين المتغيرين تقدير الذات والتحصيل الدراسي لدى الأطفال المعاقين سمعيًا بولاية الخرطوم، ولا توجد فروق في تقدير الذات لاى الأطفال المعاقين سمعيًا بولاية الخرطوم تبعًا للعمر ، وأوصت الباحثة بضرورة تأهيل ذوي الاحتياجات الخاصـة وإعادة دمجهم في المجتمع، وتثجيع البحوث العلمية لمشكلات ذوي الاحتياجات الخاصة وتطوير أساليب الرعاية لهم.

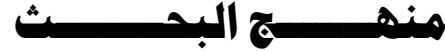

استخدم الباحثان المنهج الوصفي (الارتباطي)؛ باعتباره المنهج العلمي الأكثر مناسبة لطبيعة البحث الحالي. 


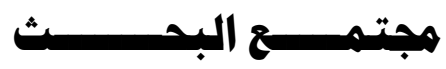

يتكوّن مجتمـع البحث الحـالي من جميع طلبـة المرحلة الجامعيـة ذوي اضطرابات الكـلام والبالغ عددهم (r/ ()) طالبًا وطالبة خلال فترة إجراء البحث خلال الفصل الدراسي الأول من العام

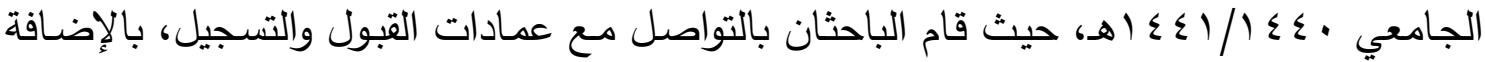
للتواصل مـع نوادٍ تطوعيّة ومراكز تدريب في المملكة العربية السعودية، تُعنى بذوي اضطرابات الكلام وتسجيل الإحصاءات وفقًا لمتطلبات البحث.

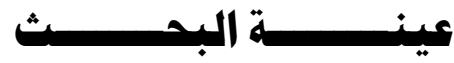

يشترط في اختيار العيّنة ما يلي:

• أن يكون طالبًا أو طالبة في إحدى الجامعات أو الكليات في المملكة العربية السعودية. • أن يكون من ذوي اضطرابات الكلام، وألّا يمانع المشاركة في تطبيق البحث.

ولمحدوديـة مجتمـع البحث تم تطبيق أدوات البحث على كامل مجتمـع البحث بأسلوب الحصر الشامل، وبعد التطبيق الميداني تم الحصول على (70 1) أداة صسالحة للتحليل الإحصائي

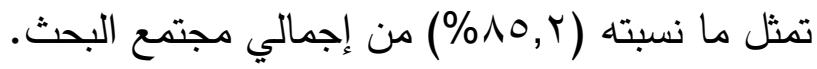

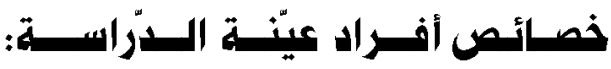

تم تحديد عدد من المتغيرات الرئيسة لوصف أفراد عيّنة الذّراسة، وتشمل: (الجنس - طالب جـامعي- اســم الجامعـة- المعـدل التراكمي في الجامعـة- المعـل التراكمي للطالب - المسـتوى الدراسي - نوع اضطرابات الكلام)، والتي لها مؤشرات دلاليّة على نتائج الدّراسة، بالإضافة إلى أنها تعكس الخلفية العلمية لأفراد عيّنة الدّراسة، وتساعد على إرساء الدعائم التي تُبنى عليها التحليلات المختلفة المتعلقة بالدّراسة.

$$
\text { استبانة تقدير الذات مكونة من ثلاثة أقسام، وهي: }
$$

القسـم الأول: يحتوي على مقدمـة تعريفيـة بأهداف البحث، ونوع البيانـات والمعلومـات التي يـود الباحثان جمعها من أفراد عينة البحث، مع تقديم الضمان بسرية المعلومات المقدمة، والتعهد باستخدامها لأغراض البحث العلمي فقط. 
القسم الثاني: يحتوي على البيانات الأولية الخاصة بأفراد عينة البحث، والمتمثلة في: (الجنس طالب جامعي -اسم الجامعـة - المعدل التراكمي في الجامعـة - المعدل التراكمي للطالب - المستوى الدراسي - نوع اضطرابات الكلام).

القسم الثالث: استبانة تقدير الذات وتمثلت في (9 (1) عبارة، منها فقرات ذات اتجاه ايجابي وأخرى ذات اتجاه سلبي، والإجابة عليها تتدرج حسب طريقة ليكرت (موافق بشدة، موافق، محايد،

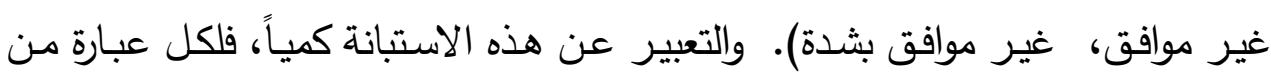
العبارات الإيجابية درجة تعطى بطريقة تتازلية، وفقاً للتالي: موافق بثدة (0) درجات،

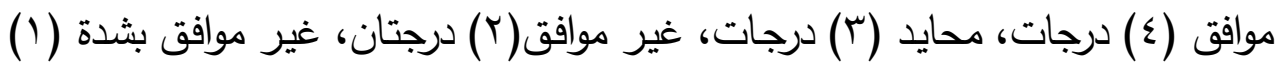

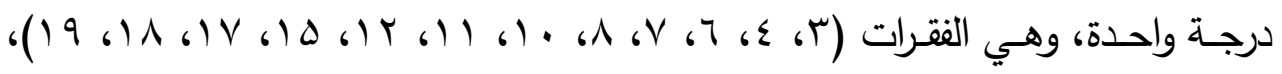

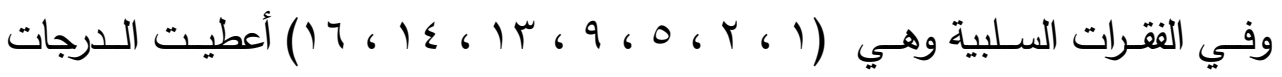
بطريقة تصاعدية، وفقاً للتالي: موافق بثدة ( () درجة واحدة، موافق (Y) درجتان، محايد (ץ) درجات، غير موافق (§) درجات، غير موافق بثدة (0) درجات.

\section{السيكومستريسـة لأداة البــث

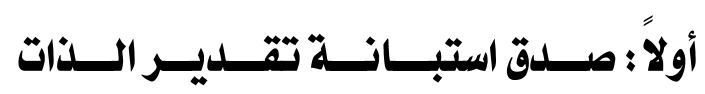 \\ ا- الصدق الظاهري (صدق المحكّمين):}

للتعرف على مدى الصدق الظاهري لاستبانة تقدير الذات، تم عرضها بصورتها الأولية على مجموعة من الخبراء في تخصصي علم النفس والتربية الخاصة لإبداء آرائهم في صـاحيتها وتقييم جودتها ومدى تمثلها للسمة المراد قياسها، والحكم على مدى ملاءمتها لأهداف البحث، وذلك من خلال تحديد وضوح العبارات، وانتمائها للدحور ، وأهميتها، وسلامتها لغوياً، وإبداء ما يرونه من هن تعديل، أو حذف، أو إضافة للعبارات، حيث وصل عدد المحمين إلى (· ( ) محكمين، وفي ضوء آراء الخبراء والاطـلاع على الملحوظـات، تم إجراء التعديلات اللازمـة التي اتفق عليها غالبيـة المحكمين، كما استبقى الباحثان على الفقرات التي تم الاتفاق عليها بنسبة (•^) فأكثر ، ومن ثم إخراج الاستبانة بصورتها النهائية. 

للتحقق من صدق الاتساق الداخلي لاستبانة تقدير الذات، تم حساب معامل ارتباط بيرسون (Pearson's Correlation Coefficient) الاستبانة بالدرجة الكلية للمحور الذي تتتمي إليه العبارة، وتوضح الجداول التالية معاملات الارتباط. جدول ( ) معاملات ارتباط بيرسون بين درجة كل عبارة من عبارات استبانة تتلدير الذات مع اللدرجة الكلية للمحور

\begin{tabular}{|c|c|c|c|}
\hline \multicolumn{4}{|c|}{ 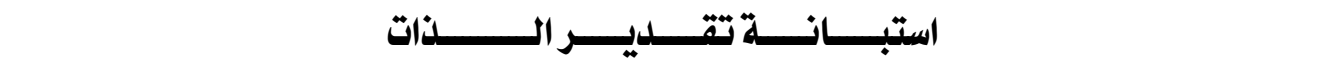 } \\
\hline معامل الارتباط بالمحور & رقم العبارة & معامل الارتباط بالمحور & رقمر العبارة \\
\hline$* *, V T I$ & 11 & $* *, \wedge \circ \mathrm{V}$ & 1 \\
\hline$* *, \vee \vee 9 \vee$ & ir & $* *, \neg \wedge \vee$ & r \\
\hline$* *,, \vee \neg \wedge$ & Ir & **, orr & r \\
\hline$* *, \vee \vee 9 \wedge$ & $1 \leq$ & $* *, V M r$ & $\varepsilon$ \\
\hline$* *, \wedge \backslash 1$ & 10 & $* *, 7 \leq 9$ & 0 \\
\hline **, , Vro & 17 & $* *, \wedge \varepsilon$ & 7 \\
\hline$* *, \wedge \circ$ & iv & $* *, \wedge \leq r$ & $\checkmark$ \\
\hline$* *, \wedge \circ$ & 11 & $* *, \wedge \circ \leq$ & $\Lambda$ \\
\hline$* *, \wedge \wedge$ & 19 & $* *, \vee \vee \wedge \varepsilon$ & 9 \\
\hline- & - & $* *, 917$ & 1. \\
\hline
\end{tabular}
*** دال عند مستوى الدلالة ا .,. فأقل

يتضـح من جدول ( () أن قيم معامل ارتباط كل عبارة من العبارات مـع بُعدها موجبة، ودالة إحصـائياً عند مستوى الدلالـة (1 . . •) فأقل؛ ممـا يشير إلى صـدق الاتسـاق الداخلي بين عبارات الاستبانة، ومناسبتها لقياس ما أُعدت لقياسه.

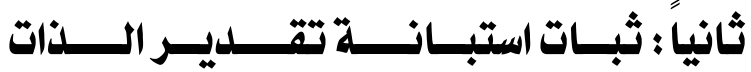

تم التأكد من ثبات استبانة تقدير الذات من خلال استخدام معامل الثبات ألفا كرونباخ (معادلة ألفا كرونباخ) (Cronbach’s Alpha (م)، ويوضح جدول (Y) قيم معاملات الثبات ألفا كرونباخ لمحاور الاستبانة. 


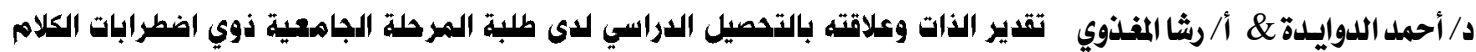

جلول (r ) معامل ألفا كرونباخ لقياس ثبات استبانة تقدير الذات

\begin{tabular}{|c|c|c|}
\hline ثبــــــات المحـــــــور & عــــــد العبــــــارات & 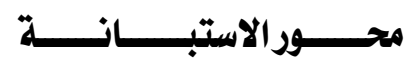 \\
\hline •, $97 \leq r$ & 19 & استبانة تقدير الذات \\
\hline
\end{tabular}

يتضح من جدول (r) أن معامل الثبات العام لاستبانة تقدير الذات بلغ (rع 9, • ).

الأساليب الإحصائية المبتفدهة في البهث

• التكرارات والنسب المئوية والانحرافات المعيارية والمتوسطات الحسابية.

$$
\text { • اختبار ت لعينة واحدة. }
$$

معامل ارتباط بيرسون (Pearson's Correlation Coefficient).

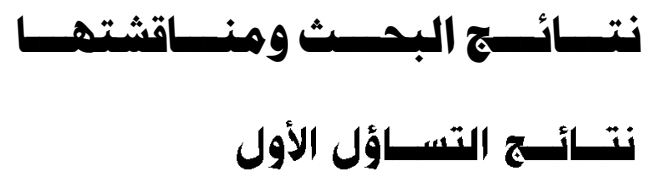

نص التساؤل الأول على: "ما مستوى تقلير الذات للى طلبة المرحلة الجامعية ذوي اضطرابات الكلاهر؟” وللإجابة على التساؤل تم حساب المتوسطات الحسابية والانحرافات المعياريـة لاستجابات

أفراد عينـة البحث على مستوى تقدير الذات لدى طلبة المرحلة الجامعية ذوي اضطرابات الكلام وجاءت النتائج كما يوضحها الجدول التالي:

جلول (r) استجابات أفراد عينة البحث على مستوى تتلدير الذات لدى طلبة المرحلة الجامعية ذوي اضطرابات الكلاه.

\begin{tabular}{|c|c|c|c|c|c|}
\hline الإحصائية & قيمة ت لعينة & الامثتوسط اضي & الانحراف & المتوسط الحسابي & \\
\hline , OYO & . & $\varepsilon \vee, 0$ & $|r, \wedge|$ & $\varepsilon 7, \vee q$ & تقدير الذات \\
\hline
\end{tabular}

يتضـح مـن خـلال النتـائج الموضـحة أعـلاه أن مستوى تقدير الذات لدى طلبـة المرحلـة

$$
\text { الجامعية ذوي اضطرابات الكلام بلغ (7,V9 ؛ ؛ وهي درجة متوسطة. }
$$

وقد أكدت نتائج اختبار ت لعينة واحدة عدم وجود فروق ذات دلالة إحصـائية عند مستوى

ه . , • بين المتوسط الفرضي للاستبانة والمتوسط الحسابي لعينة البحث على استبانة تقدير الذات 
وعند مقارنـة قيم المتوسطين أتضـح أن المتوسطين لعينة البحث والمتوسط الفرضـي كانا متقاربين مما يبين أن مستوى تقدير الذات لدى طلبة المرحلة الجامعية ذوي اضطرابات الكلام كان متوسطًا. ويفسر الباحثان هذه النتيجة بأن طلبة المرحلة الجامعية ذوي اضطرابات الكلام يعانون من عدم القدرة على التعبيـر عن أنفسهم وعدم التواصـل مـع الآخـرين وسـوء التكيف وعدم التوافق الدراسي، كما يشعرون بنقص في تقديرهم لذاتهم والتحقير منها رغم ما يجدونـه من الدعم والمساندة من أسرهم ومن زملائهم على مقاعد الدراسـة، ودعم أساتذتهم لهم، وذلك لمقارنتهم المستمرة بين أنفسهم وزملائهم في طريقة كلامهم وتفاعلهم مـع الآخرين ويؤدي ذلك لشعورهم بالنقص وتحقير أنفسهم والنظر لها نظرة دونية. وتختلف هذه النتيجة مع نتيجة دراسة (عوض الله، 10 • ب) حيث أشارت إلى ارتفاع تقدير الذات لدى طلبة المرحلة الجامعية العاديين، كما تختلف مع دراسة (الغامدي، ج 1 ـ ب) والتي أشارت إلى ارتفاع تقدير الذات لدى الطلبة المعاقين سمعياً. ويفسر الباحثان هذه النتيجة بأن الطلاب الذين كان تقديرهم لذاتهم مرتفعًا لا يعانون أيَّا من اضطرابات الكلام.

\section{نتــائســة التســاؤل الثــــــي}

نص التساؤل الثاني على: "هل توجـل علاقة ارتباطية بـين تقـلير الدات والتحصيل الدراسي للدى طلبة المرحلة الجامعية ذوي اضطرابات الكلام؟؟

وللإجابـة على التسـاؤل تم حسـاب معامل ارتباط بيرسون وجاءت النتائج كمـا يوضـحها

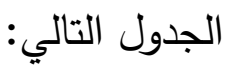
جلدول (§) نتائج معامل ارتباط بيرسوز لتحليل العلاقة بين تقدير الذاتوالتحصيل الدراسي للى طلبة المرحلة الجامعية ذوي اضطر ابات الكلاه

\begin{tabular}{|c|c|c|}
\hline التحصيل اللدراسي & & البيـــــــــــ \\
\hline$\cdot, 779$ & معامل الارتباط & \multirow{2}{*}{ تقدير الذات } \\
\hline$* *, \ldots 1$ & الدلالة الإحصائية & \\
\hline
\end{tabular}

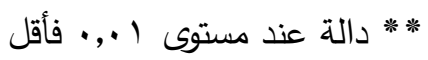


من خلال النتائج الموضحة أعلاه يتضـح وجود علاقة ارتباطية طردية دالة إحصـائيًا عند مستوى ( ( ., •) بين تقدير الذات والتحصيل الدراسي لدى طلبة المرحلة الجامعية ذوي اضطرابات الكلام. حيث يتضح أنه كلما زاد تقدير الذات لدى طلبة المرحلة الجامعية ذوي اضطرابات الكلام كلما زاد مستوى التحصيل الدراسي للديهم. ويفسر الباحثان هـذه النتيجـة بـأن تقدير الـذات مسن أهـم العوامـل المـؤثرة على التحصـيل الدراسـي، حيث إن شـور الطالب بتقدير ذات عـالٍ يسـاعده على تخطي المشكلات الأكاديميـة وضـوط الحياة الجامعيـة التي يواجهها بإيجاد حلول توافقية مناسبة وتحقيق تحصيل دراسي جيد. ارتفاع مستوى تقدير الذات لدى طلبة المرحلة الجامعية ذوي اضطرابات الكلام هو أسـاس نجاحهم حيث يعزز ثقتهم بأنفسه وشعورهم بتميزهم وبأهميتهم كأفراد فاعلين في الصف الدراسي ويحسن من مستوى تحصيلهم الدراسي. وعلى العكس فإن انخفاض تقدير الذات يفقد الطالب الجامعي ثقته بنفسه ويحد من قدراته التعليمية ويزيد من ضغوطه النفسية التي تصل به إلى ضعف التحصيل الدراسي. وتتقق هذه النتيجة مع نتيجة دراسة منال (Y V V والتي بينت وجود علاقة بين تقدير الذات والتحصيل الدراسي لدى تلاميذ مرحلة التعليم المتوسط، فكلما زاد تقدير الذات لديهم صـاحبته زيـادة في التحصيل الدراسي، وكلما انخفض تقدير الذات لوحظ انخفاض في التحصيل الدراسي لديهم. كما تتفق أيضًا مـع نتيجة دراسـة الغامدي (T ( ا ب) والتي بينت أن الطلبة أصـحاب المعدلات التراكمية المرتفعة هم أكثر تقديرًا لذاتهم. كما تتفق أيضاً مع دراسة الحاج والثايب (10 ـ ب) والتي أثتتت وجود علاقة قوية بين التحصيل الدراسي وكل من تقدير الذات الكلي والرفاقي والمدرسي والعائلي. (Noronha, Monteiro, \& Pinto, بينما تختلف نتيجة البحث الحالي مع نتيجة دراسة (2018 والتي بينت عدم وجود علاقة ذات دلالة احصائية بين تقدير الذات والتحصيل الدراسي.

في ضوء النتائج التي توصل إليها البحث الحالي، يعرض الباحثان توصياتهما كما يلي: ضرورة إعداد البرامج الإرشادية والعلاجية التي تساعد في علاج تدني تقدير الذات لدى طلبة المرحلة الجامعية ذوي اضطرابات الكلام.

الاهتمام بتشجيع طلبة المرحلة الجامعية ذوي اضطرابات الكلام على الاندماج مع زملائهم. توفير خدمات الإرشاد النفسي في الجامعات لطلبة المرحلة الجامعية ذوي اضطرابات الكلام. توفير خدمات علاجية لعلاج مشكلات الكلام لدى طلبة الجامعة داخل الحرم الجامعي. 

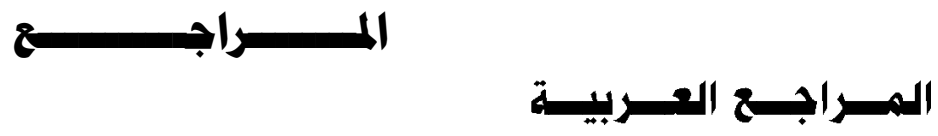

إبراهيم، إبراهيم. (11 ( ب). بعض المتغيرات الشخصية المرتبطة باضطرابات النطق والكلام لدى طــلاب المـرحلتين الابتدائيـة والمتوسـطة بالمملكـة العربيــة السـعودية. دراســة تنبؤَيــة

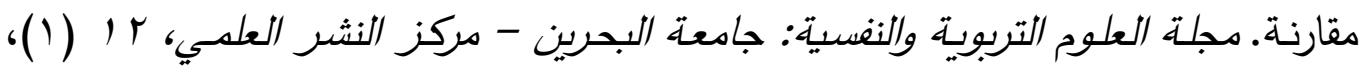

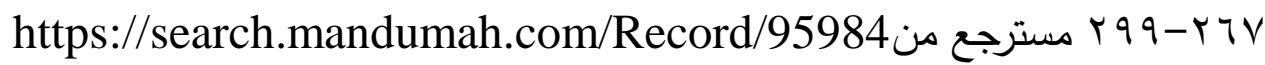
أحمد، علي. ( • ( ب). التحصيل الدراسي وعالتهه بالقيم الاسلامية والتربوية. بيروت. لبنان: مكتبة حسين العصرية.

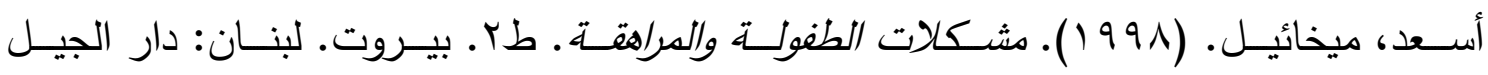
للنشر والتوزيع. الآلوسي، وفاء. (ع ( • ( ). تقدير الذات وعلاقته بمستوى التحصيل الدراسي. مجلة العلوم التربوية

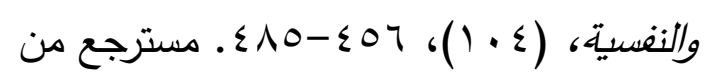

http://search.mandumah.com/Record/513781

بخاري، إبراهيم. (T 1 • ب). تدنّي التحصسيل الأكاديمي لبعض طـلاب قسم علم المعلومـات: كلية العلوم الاجتماعية، جامعة أم القرى، مكة المكرمة. مجلة مكتبة الملك فهـ الوطنية، بr r

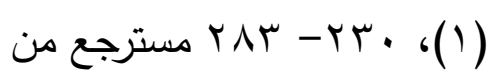

http://search.mandumah.com/Record/691573

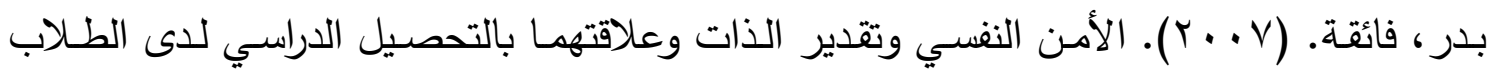
السعوديين والمغتربين بالمرحلة الابتدائية. مجلة دراسات عربية في علم النفس، 7 (Y)،

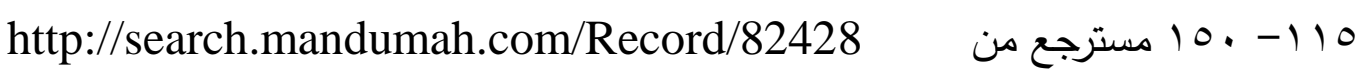

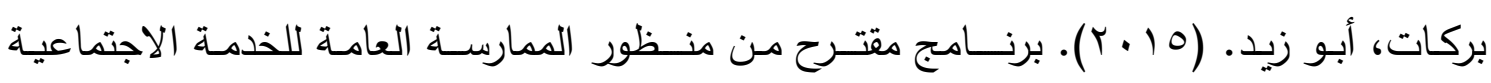

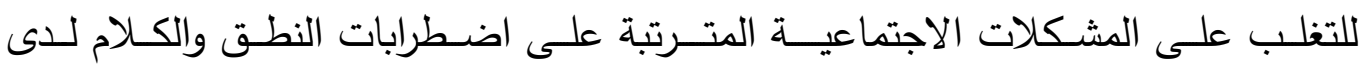

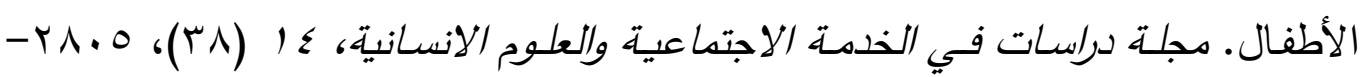

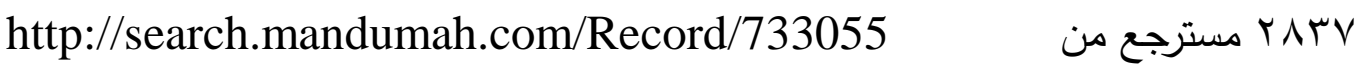
بعيبع، نادية، وزيدان، سحر • (r ( r). اضطرابات اللغة والكلام. الرياض: دار النشر الدولي. 


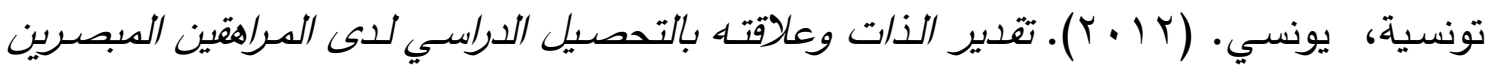
والمراهتين الدكفوفين، دراسة ميد/نية بولايتي تيزي وزو والجزائر العاصدة (رسالة ماجستير

غير منشورة)، جامعة مولود معمري، الجزائر ـ مسترجع من

http://lib1.qsm.ac.il/rsael/tqder\%20althat.pdf

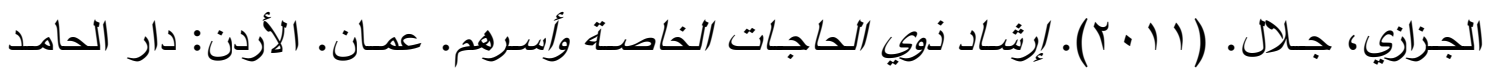
للنشر والتوزيع.

الحاج، قدوري، والثشايب، محمد. (10 • r). تقدير الذات (الرفاقي والمدرسي والعائلي) وعلاقته

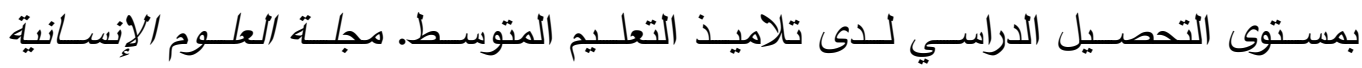

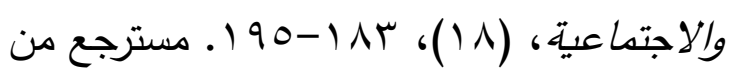

http://search.mandumah.com/Record/638131

حـافظ، بطـرس. (^ . . ץ). التكتيّف والصـحة النفسـية للطفـل. عمـان، الأردن: دار المسـيرة

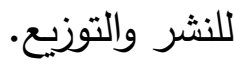

حبيب، سالي. (T ( • (Y). فاعليّة برنامج تدريبي باستخدام السيكودراما لتتمية التفاعل الاجتماعي

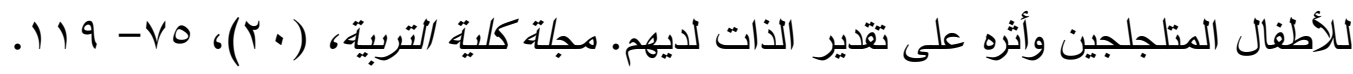
http://search.mandumah.com/Record/882688 مسترجع من م الحريري، رافدة. (· ( • ( ). طرق التدريس بين التقلي والتجديد. عمان، الأردن: دار الفكر للنشر . الحموي، منى. (· ( • ( ). التحصيل الدراسي وعلاقته بمفهوم الذات (دراسة ميدانية على عينّة من تلاميذ الصف الخـامس -الحلقة الثـــانية- من التعليم الأســاسي في مدارس محافظـة

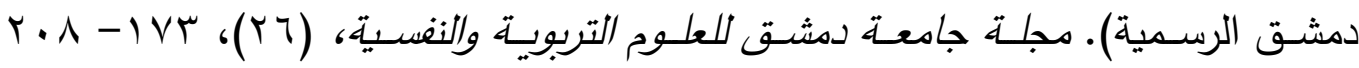
http://search.mandumah.com/Record/97849 مسترجع من م

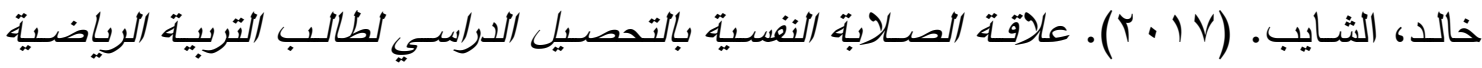
والبندية. رسالة ماجستير، جامعة قاصدي مرباح ورقلة، الجزائر.

ديب، فتيحة. (ع ( • Y). أهمية تقدير الذات في حياة الفرد.مجلحة العلوم الإنسانية والاجتماعية:

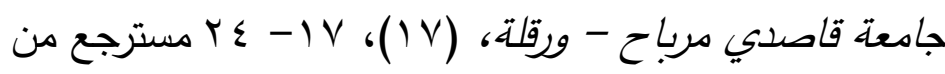
https://search.mandumah.com/Record/637934 
رجيعة، عبد الحميد. (0 1 ب ( ). رهاب الكلام وعلاقته بالثقة بالنفس وبعض أبعاد الشخصية لدى

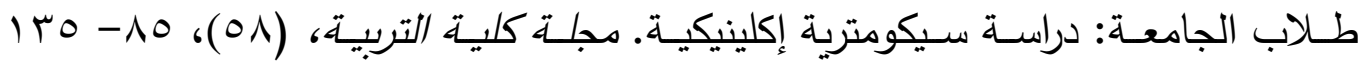
http://search.mandumah.com/Record/740638 مسترجع من الزريقات، إبراهيم. (1 ( • r). اضطرابات الكسلام واللغة. التشخيص والعلاج. طح. عمان، الأردن: دار الفكر .

ساسي، آمنة. (V V • Y). الضغوط النفسية لدى عيّنة من الطالبات المتزوجات بكلية التربية جامعة

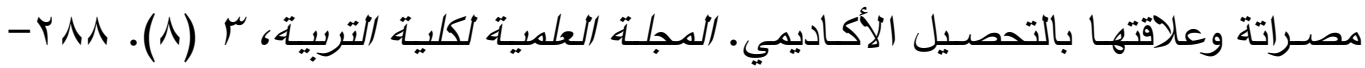
http://search.mandumah.com/Record/827143 ا I. مسترجع من سـالم، هبـة الله. (T ( • Y). قلق الاختبار وعلاقته بموضـع الضـبط والضـغوط النفسية والتحصيل الدراسـي لدى طالبــات كليـة التربيــة جــامعة حائل بالمملكـة العربيـة السعودية. العلوم

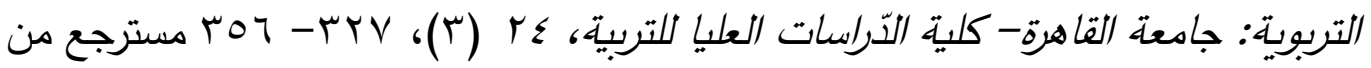
https://search.mandumah.com/Record/795753

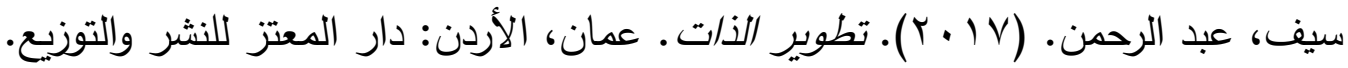

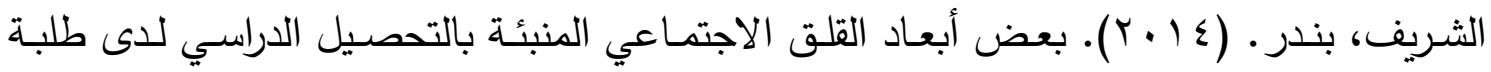
جامعة طيبة. المجلة التربوية الدولية المتخصصة،r (9)، ا - r r مسترجع من http://search.mandumah.com/Record/843175 الثـعيلي، علي، والبلوشـي، محمد. (ج . . r). دراسـة تحليليـة للعوامل التربويـة المؤديـة إلى تدني تحصــيل طــلاب الثــهادة العامــة للتعلـيم العــام فـي الفيزيــاء كمــا يراهــا المعلمــون والمشرفون مجلـة /تحاد الجامعات العربية للتربية وعلم النفس: جامعسه دمشق - كليه

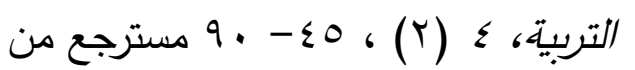

https://search.mandumah.com/Record/105548

$$
\text { شقير ، زينب. (1 ( • r). اضطرابات اللغتة والتواصل، طب. الرياض، دار الزهراء. }
$$
الثيخ، حنان. (1 ( ـ ( ). اضطرابات اللغتة والكلام. طr. الكويت: مكتبة الفلاح للنشر والتوزيع 


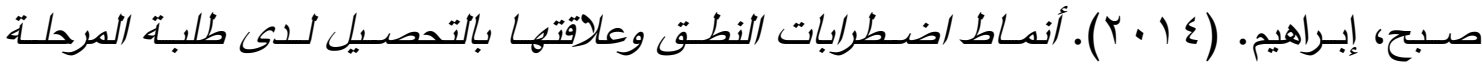
الأساسية الـنيا من وجهة نظـر المعلدين في محافظـة جرش (رسـالة ماجستير غير

$$
\text { منشورة). جامعة عمان العربية، عمّان. مسترجع من }
$$

http://search.mandumah.com/Record/635586

الظاهر ، قحطان. (• • ( ). اضطرابات اللغة والككلام. عمان. الأردن: دار وائل للنشر والتوزيع. الظاهر، قحطان. (• ( • ( ). مغهوم الذات بين النظرية والتطبيق. طr. عمان. الأردن: دار وائل

$$
\text { للنشر والتوزيع. }
$$

العاتي، سعاد. (10 • ( ). علاقة تقدير الذات بالقلق الاجتماعي لدى طلبة سنة أولى إنجليزي.. دراسة على عيّنة من طلبة سنة أولى إنجليزي بجامعة قاصدي مرباح - ورقلة (رسالة ماجستير غير منشورة). جامعة قاصدي مرباح - ورقلة، ورقلة. مسترجع من https://search.mandumah.com/Record/935957 عاشور ، وفاء. (10 • ب). الإهمال الأسري وعلاقته بالتحصيل الدراسي للى تلاميذ السنة الرابعة من التعليم الدتوسط، رسالة ماجستير، جامعة الوادي، الجزائر. عامر ، طارق. (1 ( • r). دفهوم وتقدير الذات. القاهرة. مصر : دار العلوم للنشر والتوزيح. عبد العزيز، حنان. (r ( r). أنداط التفكير وعلاقتها بتقدير الذات، رسالة ماجستير ، الجزائر . https://platform.almanhal.com/details/article/84064\# مسترجع من عبد الفتاح، مصطفى. (ب99 (1). موسوعة علم النفس التحليلي النفسي. بيروت، لبنان: دار سعاد الصباح.

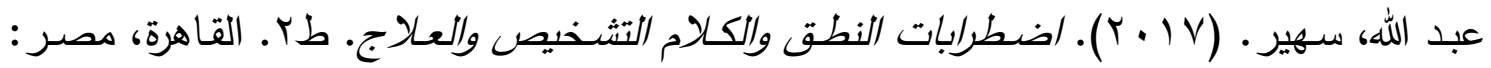
دار الفكر العربي.

عبد المطلب، عبد القادر • (10 + ب). بعض الخصائص النفسية والثخصية لدى طلاب المرحلة الثانوية المصابين باضطراب اللجلجة في الكلام.مجلة العلوم الاجتماعية: جامعة الكويت

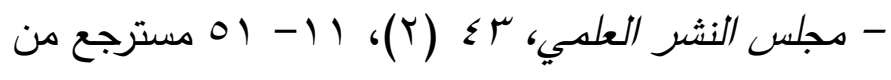

https://search.mandumah.com/Record/688384 


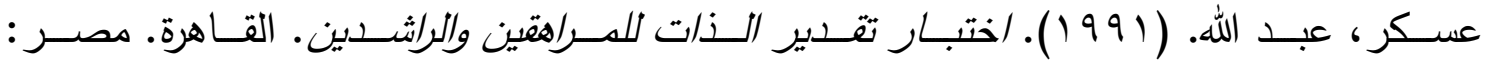
مكتبة الأنجلو المصرية.

عوض الله، شيرين. (10 • ب). تقدير الذات وعلاقته بالتحصيل الدراسسي لدى الأطفال الدعاقين سمعيًّ بدعهُ الأمل (رسالة ماجستير غير منشورة). جامعة النيلين، الخرطوم. مسترجع من https://search.mandumah.com/Record/831469

عيد، يوسف. (0 1 • ب). اضطرابات الكلام وعلاقتها بتقدير الذات والقلق بمصر والسعودية.. دراسة

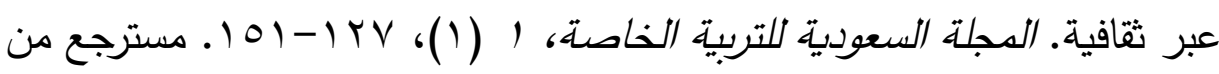
http://serch.mandumah.com/Record/800190 العيسوي، عبد الرحمن. ( . . . r). أمراض العصر. الأمراض النفسية والعقلية والسيكوسوماتية. الاسكندرية. مصر : دار المعرفة الجامعية. الغامدي، صالح. (9 + . r). اضطرابات الكلام وعلاقتها بالثقتة بالنفس وتقدير الذات للى عيّتة من طلاب

المرحلة المتوسطة (رسالة دكتوراة غير منشورة)، جامعة أم القرى، قسم علم النفس، السعودية. الغامدي، علي. (7 1 • ب). تقدير الذات وعلاقته ببعض المتغيرات لدى طلاب قسم التربية البدنية بجامعة أم القرى. المجلة التربوية الدولية المتخصصتة، ه (Y)، ا -7 ا مسترجع من http://search.mandumah.com/Record/844141 قطب، رشيدة. (91991). آفاق معاصرة في الصحة النفسية للأبناء، القاهرة، مصر : دار الكتب العلمية للنشر والتوزيع.

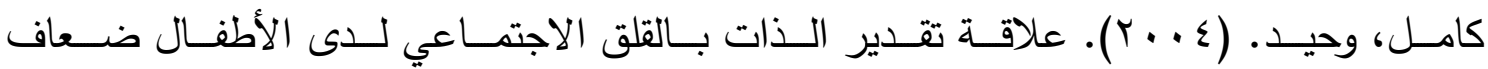

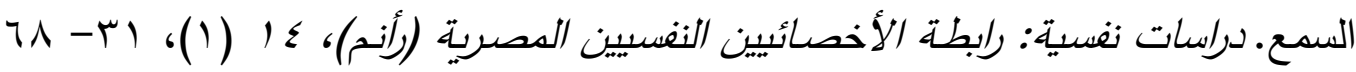

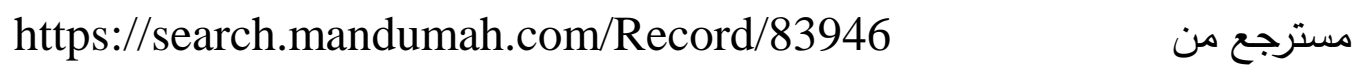
اللحياني، مريم، والعتيبي، سميرة. (• ( • ( ). تقدير الذات لدى الطلاب الموهوبين والمتفوقين متدنّي التحصيل الدراسسي: قراءة سيكولوجية. المؤتمر العلمي العربي السـابع لرعايـة الموهوبين والمتفوقين - أحلامنا تتحقق برعاية أبنائنا الموهوبين: المجلس العربي للموهوبين والمتفوقين، ج r، عمان: المجلس العربي للموهوبين والمتفوقين وواجهة الأردن للتعلم والتبادل الثقافي،

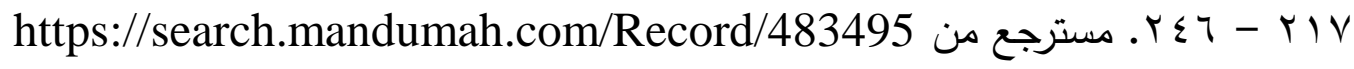


مجلي، شايع؛ بلان، كمال؛ والمذحجي، منصور • (T ( ب). تقدير الذات وعلاقته بالسلوك العدواني لاى طلبة الصف الثامن من مرحلة التعليم الأساسي بمدينة صعدة. مجلة جامعة دمشق لق

$$
\text { للعلوم التربوية والنفسية: جامعت دمشق، } 9 \text { r (1)، 09- ع ـ ا مسترجع من }
$$

https://search.mandumah.com/Record/487857

محمد، خلود. (1 ا • r). المساندة الاجتماعية وعالاقتها بالتحصيل الدراسي لدى طلبة الصف الثاني والثالث للتعليم الثانوي بدينتة سبها ـ كلية الآداب، جامعة سبها. مسترجع من

http://dspace.idpsebhau.edu.ly//handle/1/630

محمود، الفرحاتي. (11 (Y). علم النفس الإيجابي للطفل . القاهرة، مصر: دار الجامعة الجديدة. مراكثـي، مـريم، ورمـزى، مـراد. (1) • ( ). جـودة الحيـاة وعلاقتهـا بتقدير الـذات لـدى الطلبـة الجامعيين.. دراسة ميدانية على عينّة من طلبة جامعة سطيف r . مجلة الحكمة للدراسات

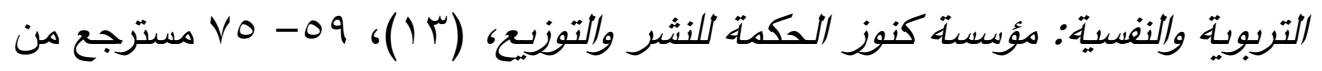
https://search.mandumah.com/Record/869834

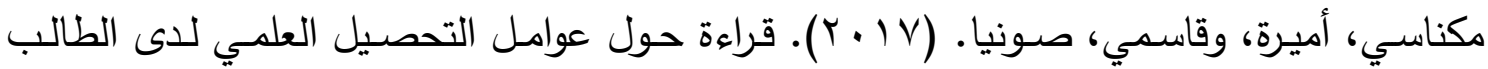

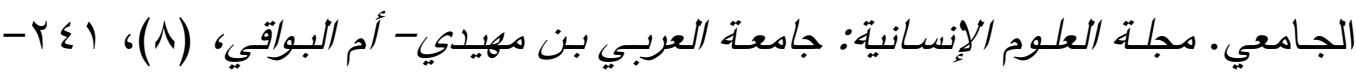
https://search.mandumah.com/Record/937095 مسترجع من

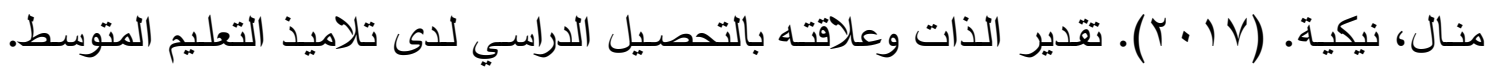

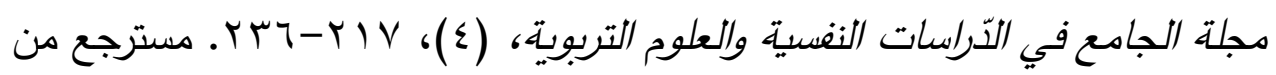
http://search.shamaa.org/PDF/Articles/AEAjjpses/AjjpsesNo4Y2017/Ajjps es_2017-n4_217-236.pdf

نمر ، سهام. (1 ( • ( ). أحلام اليقظة وعلاقتها بتقدير الذات لدى طالبات المرحلة الثانويـة، مجلة العلوم النفسية، (9 (1)، جامعة بغداد. مسترجع من

https://www.iasj.net/iasj?func $=$ fulltext\&aId=2731

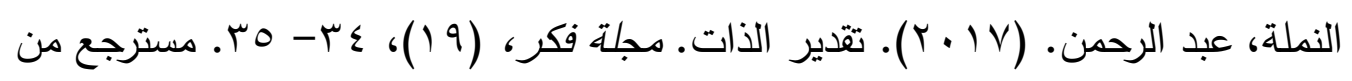

http://search.mandumah.com/Record/825233 
American Speech-Language-Hearing Association (ASHA).(1993).

Definitions of Communication Disorders and Variations. Retrieved 8 June, 2019, from https://www.asha.org/policy/RP1993-00208.htm

Arshad, M., Zaidi, S. M. I. H., \& Mahmood, K. (2015). Self-Esteem \& Academic Performance among University Students. Journal of Education and Practice, 6(1), 156-162.

Bahrami, D., \& Bahrami, M. A. (2015). The relationship of self-esteem and achievement goals with academic performance. African Journal of Basic \& Applied Sciences, 7(1), 65-72.

Blood, G. Tellis, G. (2003). A preliminary study of self-esteem, stigma, and disclosure in adolescents who stutter. Journal of Fluency Disorders, 6(28), 169- 179.

Blood, G. W., \& Blood, I. M. (2016). Long-term consequences of childhood bullying in adults who stutter: Social anxiety, fear of negative evaluation, self-esteem, and satisfaction with life. Journal of fluency disorders, 50, 72-84.

Bloodstein, O., \& Bernstein Ratner, N. (2008). A handbook on stuttering (6th ed.). Clifton Park, NY: Delmar.

Cvencek, D., Fryberg, S. A., Covarrubias, R., \& Meltzoff, A. N. (2018). Self-concepts, self-esteem, and academic achievement of minority and majority north American elementary school children. Child development, 89(4), 1099-1109.

Davis, S. Cooke, F.(2002). Sociodynamic relationships between children who stutter and their non-stuttering classmates. Journal of Child Psychology and Psychiatry,.5 (34), 939-947. 
د/أحمدالدوايلدة \& أ/رشا المفذوي تقدير الذات وعلاقته بالتصيل الدراسي لدى طلبة المرحلة الجامعية ذوي اضطرابات الكلام

Hudson, J. L., \& Rapee, R. M. (2009). Familial and social environments in the etiology and maintenance of anxiety disorders. Oxford handbook of anxiety and related disorders, 173-189.

Iverach, L., \& Rapee, R. M. (2014). Social anxiety disorder and stuttering: Current status and future directions. Journal of fluency disorders, 40, 69-82.

Iverach, L., Rapee, R. M., Wong, Q. J., \& Lowe, R. (2017). Maintenance of social anxiety in stuttering: a cognitive-behavioral model. American Journal of Speech-Language Pathology, 26(2), 540-556.

Jirdehi, M. M., Asgari, F., Tabari, R., \& Leyli, E. K. (2018). Study the relationship between medical sciences students' self-esteem and academic achievement of Guilan University of medical sciences. Journal of education and health promotion, 7.

Körük, S. (2017). The effect of self-esteem on student achievement. In The factors effecting student achievement (pp. 247-257). Springer, Cham.

Kožuh, Ines; Jeremic, Zoran; Sarjaš, Andrej; Bele, Julija Lapuh; Devedžic, Vladan; Debevc, Matjaž (2015). Social Presence and Interaction in Learning Environments: The Effect on Student Success. Educational Technology \& Society, v18 n1 p223-236.

Liaqat, S., \& Akram, M. (2014). Relationship between Self-Esteem and Social Anxiety among Physically Handicapped People.

Noronha, L., Monteiro, M., \& Pinto, N. (2018). A Study on the Self Esteem and Academic Performance Among the Students. International Journal of Health Sciences and Pharmacy (IJHSP), 2(1). 